\title{
Inactivation by UV-Radiation and Internalization of Coliforms and Escherichia coli in Aquaponically and Hydroponically Grown Lettuce
}

Matthew J. Moriarty

Follow this and additional works at: https://researchrepository.wvu.edu/etd

\section{Recommended Citation}

Moriarty, Matthew J., "Inactivation by UV-Radiation and Internalization of Coliforms and Escherichia coli in Aquaponically and Hydroponically Grown Lettuce" (2014). Graduate Theses, Dissertations, and Problem Reports. 6263.

https://researchrepository.wvu.edu/etd/6263

This Thesis is protected by copyright and/or related rights. It has been brought to you by the The Research Repository @ WVU with permission from the rights-holder(s). You are free to use this Thesis in any way that is permitted by the copyright and related rights legislation that applies to your use. For other uses you must obtain permission from the rights-holder(s) directly, unless additional rights are indicated by a Creative Commons license in the record and/ or on the work itself. This Thesis has been accepted for inclusion in WVU Graduate Theses, Dissertations, and Problem Reports collection by an authorized administrator of The Research Repository @ WVU. For more information, please contact researchrepository@mail.wvu.edu. 


\section{Inactivation by UV-Radiation and Internalization of Coliforms and Escherichia coli in Aquaponically and Hydroponically Grown Lettuce}

Matthew J. Moriarty

Thesis submitted to the

Davis College of Agriculture, Natural Resources, and Design

at

West Virginia University

in partial fulfillment of the requirements

for the degree of

Master of Science

In

Nutritional and Food Science

Jacek Jaczynski, Ph.D., Chair

Gary K. Bissonnette, Ph.D.

Kenneth Semmens, Ph.D.

Division of Animal and Nutritional Sciences

Morgantown, West Virginia

2014

Keywords: Escherichia coli, coliforms, aquaponics, hydroponics, internalization, fecal contamination

Copyright 2014 Matthew J. Moriarty 


\section{ABSTRACT \\ Inactivation by UV-Radiation and Internalization of Coliforms and Escherichia coli in Aquaponically and Hydroponically Grown Lettuce}

\section{Matthew J. Moriarty}

Recent studies have shown that coliform bacteria, specifically Escherichia coli O157:H7, can internalize in leafy green produce. Therefore, a risk exists for lettuce being grown in systems using mixed water sources. Additionally, Ultra Violet light radiation has been shown to inactivate coliforms in water. For this reason, an experiment was conducted at West Virginia University's aquaculture facility to determine the effect of UV-radiation in water supplying an aquaponic channel with nutrients, and to assess the risk of coliform and E. coli internalization. In this experiment, the spring fed, flow-through aquaponic system was receiving runoff from cattle pastures as a source of coliform bacteria. An inline UV-light system was randomized to treat water going to half of the hydroponic channels growing lettuce downstream from the raceways containing fish. Water going into and leaving the eight channels was sampled for 6 weeks in addition to the upstream water (before and after the fish raceways). Additionally, lettuce samples were aseptically collected during the time of harvest. Water samples were plated directly on 3-M Petrifilm EC (E. coli/ coliform) as well as on M-endo agar using a membrane filter. Incubation was done at $35^{\circ} \mathrm{C}$ for $48 \mathrm{~h}$ for both media. Lettuce samples were surface sanitized, homogenized, and directly plated on M-endo agar. The mean coliform count of all untreated water was $1.93 \mathrm{x}$ $10^{1} \mathrm{CFU} / \mathrm{ml}$. A 3-4 Log reduction in total coliforms for treated water entering the channels was observed. There were no detectable levels of E. coli in the treated water entering the channels; the mean concentration of untreated water was $0.69 \mathrm{CFU} / \mathrm{ml}$. Additionally, internalized coliforms were not detected in the lettuce samples. Although, black colonies did grow on the media, they tested negative in a confirmation test; discoloration was most likely due to the decomposition of the lettuce particles within the samples. This study demonstrates the effectiveness of coliform inactivation by UV-radiation in water and suggests that coliform/E. coli internalization in lettuce may be a conditional phenomenon.

In efforts to verify the possibility of internalization in lettuce grown in water, as well as its dependence on conditional factors, a follow-up study was conducted at West Virginia University. The objective of this study was to determine the level in which internalization of $E$. coli occurs in lettuce as well as the effect plant root injury may have on it within a hydroponic system. A hydroponic system was set up to grow lettuce in water inoculated with Escherichia coli $\mathrm{O} 157: \mathrm{H} 7$. The inoculated water was kept at a concentration around $10^{5} \mathrm{CFU} / \mathrm{ml}$ of $E$. coli O157:H7 for the duration of this study. Half of the plants were randomized to receive 3 consecutive treatments of damage to the root tips. Edible portions of the lettuce were then harvested to be analyzed. The lettuce was surface-sanitized, homogenized, and filtered using a bag mixer. Sample dilutions were prepared and inoculated on 3-M Petrifilm EC. Internalization was observed at a mean of $1.66 \times 10^{1} \mathrm{CFU} / \mathrm{g}$ in both treated and untreated plants and as high as $4.90 \times 10^{4} \mathrm{CFU} / \mathrm{g}$ in one treated sample. Although there was no significant difference between treatment and the control, it should be stated a difference was observed. Taking into account the sample size used, significance may be seen if this were repeated on a larger scale. The variation within the samples may also suggest other contingent conditions may be a factor. 


\section{Acknowledgments}

I would like to thank my advisor for all the support and guidance he has given throughout my graduate studies. This research was funded through a Specialty Crop Block Grant with the WV Department of Agriculture. Special thanks to Dr. Kenneth Ryan of West Virginia University

for assistance with statistical analysis and Sarah K. Beamer for assistance in obtaining equipment and materials. Special thanks to my committee members, Dr. Kenneth Semmens and Dr. Gary Bissonnette for all their time, effort, and support they have given me throughout this research. I would like to thank the staff at Reymann Memorial Farm, specifically Matthew Ferrell and Eugene Jacobs, for planting the trays and providing daily inspection of the channels to assure that the system operated properly. 


\section{TABLE OF CONTENTS}

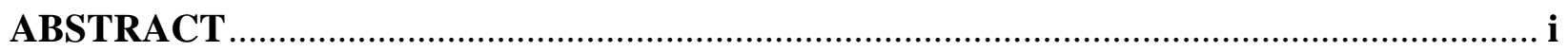

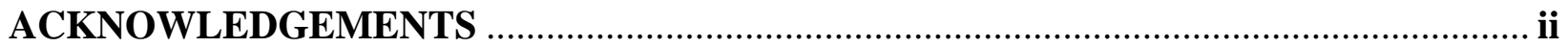

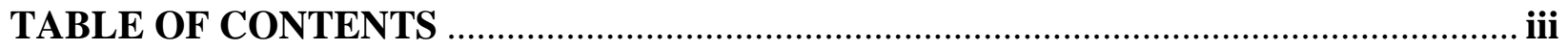

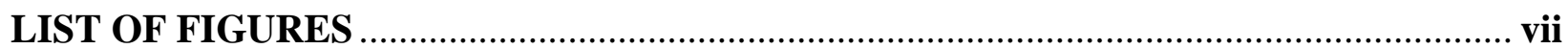

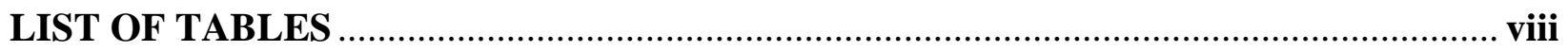

CHAPTER 1: Inactivation with UV-Radiation and Internalization of Coliforms and Escherichia coli in Aquaponically Grown Lettuce ...............................................................................

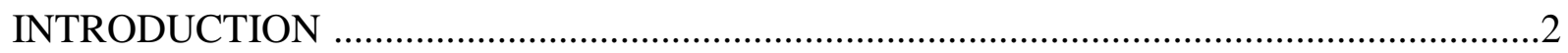

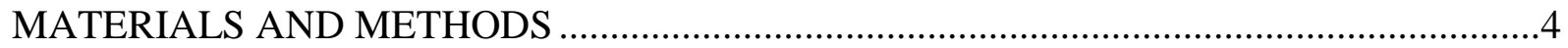

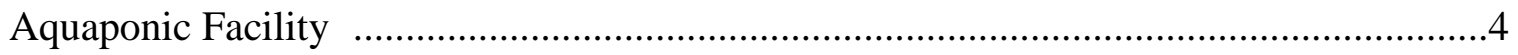

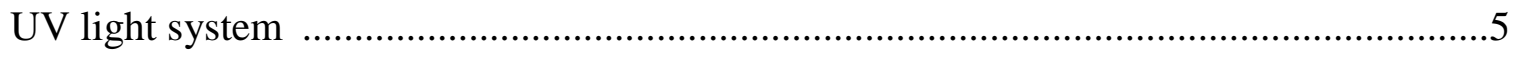

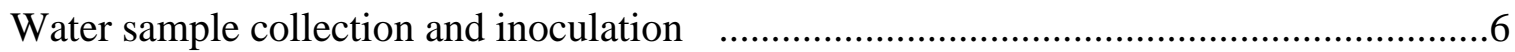




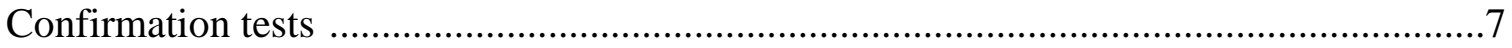

Sampling of lettuce and detection of internalization ………..........................................

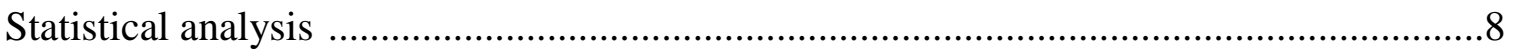

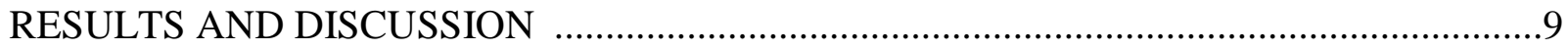

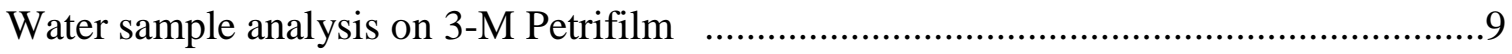

Water sample analysis on M-endo agar ………........................................................10



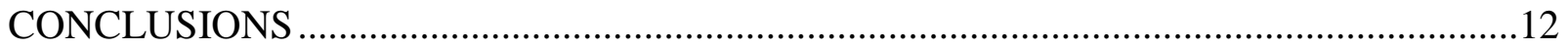

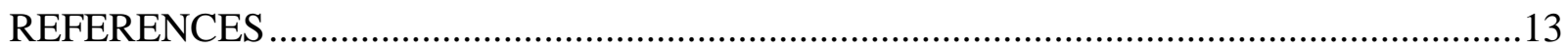

Figure 1: Detected colonies on 3-M Petrifilm over 6 weeks ..................................................16

Figure 2A: Mean Log count for large colonies on 3-M Petrifilm (CFU/ml) ………...............17

Figure 2B: Mean Log count for small colonies on 3-M Petrifilm (CFU/ml) ………..............18

Figure 3A: Represents variance of large colonies seen on 3-M Petrifilm …….....................19

Figure 3B: Represents variance of small colonies seen on 3-M Petrifilm .............................20

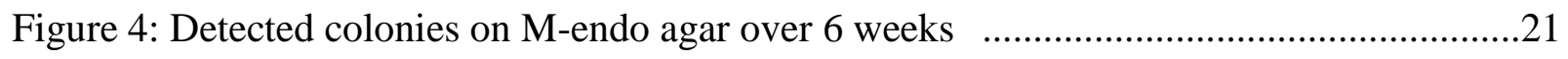


Figure 5A: Mean Log count for green colonies on M-endo agar .22

Figure 5B: Mean Log count for red colonies on M- endo agar .23

Figure 6A: Represents variance of green colonies seen on M-endo agar .24

Figure 6B: Represents variance of red colonies seen on M-endo agar .25

Figure 7A: Diagram of aquaculture facility .26

Figure 7B: Diagram of aquaculture greenhouse. .27

Table 1: Shows the mean Log difference between treated and untreated water 3-M Petrifilm 28

Table 2: Shows the mean Log difference between treated and untreated on M-endo agar .29

CHAPTER 2: Internalization of E. coli O157:H7 in Hydroponically Grown Lettuce with Randomized Injury Afflicted on Roots

INTRODUCTION

Hydroponic Tank .33

Growing conditions .34

Inoculation and monitoring of E. coli O157:H7. .34

Injury to lettuce roots 
Harvest and sterilization of lettuce .36

Statistical Analysis .37

RESULTS AND DISCUSSION .37

Analysis of Growth Conditions

Microbiological analysis of water .38

Microbial Analysis of Lettuce

CONCLUSIONS

REFERENCES

Figure 1: Descriptive analysis showing variation between data points for the Log of E. coli O157:H7 per gram of lettuce subjected to injury.

Figure 2: Mean Log of E. coli O157:H7 per gram of lettuce with amount of injury administered.

Figure 3: Mean Log of E.coli O157:H7 per gram of lettuce subjected injury. .46

Table 1: The concentration of $E$. coli the tank for each sampled day and when pure culture $E$. coli $\left(10^{9} \mathrm{CFU} / \mathrm{ml}\right)$ was added.

Table 2: Statistical measures including highest seen concentration of E. coli (Max CFU), mean values \pm standard deviation (SD), and mean difference \pm standard error (SE). 48 


\section{LIST OF FIGURES}

\section{CHAPTER 1 FIGURES}

Figure 1: Colonies on 3-M Petrifilm over time

Figure 2A: Mean Log for large colonies on 3-M Petrifilm

Figure 2B: Mean Log for small colonies on 3-M Petrifilm

Figure 3A: Variance of large colonies

Figure 3B: Variance of small colonies

Figure 4: Colonies on M-endo over time

Figure 5A: Mean Log for green colonies on M-endo over time

Figure 5B: Mean Log for red colonies on M-endo over time.....

Figure 6A: Variance of green colonies

Figure 6B: Variance of red colonies .25

Figure 7A: Diagram of aquaculture facility .... .26

Figure 7B: Diagram of aquaculture greenhouse.

\section{CHAPTER 2 FIGURES}


Figure 1: Variation in lettuce samples

Figure 2: Mean Log of E. coli for lettuce with amount of treatment applied .45

Figure 3: Mean $\log$ of $E$. coli for treated and untreated lettuce .46

LIST OF TABLES

CHAPTER 1 TABLES

Table 1: Mean Log difference between treatments and control for 3-M Petrifilm .28

Table 2: Mean Log difference between treatments and control for M-endo

\section{CHAPTER 2 TABLES}

Table 1: Reported concentration of tank water E. coli and days added

Table 2: Mean Log, Mean Log difference, and Maximum CFU/g found .48 1 
1

2

3

4

5

6

7

8

9

10

11

12

13

14

15

16

17

18

19

0

1

4

7

9

CHAPTER 1: Inactivation with UV-Radiation and Internalization of Coliforms and Escherichia coli in Aquaponically Grown Lettuce

Matthew J. Moriarty

8

列

2

3

Division of Animal and Nutritional Sciences, West Virginia University, Morgantown, West Virginia, 26506 


\section{INTRODUCTION}

Outbreaks in food borne illnesses traced back to fresh produce and associated with human enteric pathogens have been increasing in recent years (Macarisin, Patel, \& Sharma, 2014; Deering, Mauer, \& Pruitt, 2012). The proportion of food borne outbreaks associated with produce has increased from $0.7 \%$ in the 1970 's to over $6 \%$ in the 1990 's (Sivapalasingam,

Friedman, Cohen \& Tauxe, 2004). In a case study reviewing outbreaks between 1982 and 2002, 350 reported outbreaks accounted for 8,598 cases of E. coli O157:H7 infections in the United State (Rangel, Sparling, Crowe, Griffin \& Swerdlow, 2005). Transmission routes for 183 of these outbreaks were found to be food borne of which $21 \%$ of them were linked to produce (Rangel, Sparling, Crowe, Griffin \& Swerdlow, 2005). One particular concern of food borne outbreaks involving produce is with fecal contamination. This includes the contamination of produce with the enteric pathogen Escherichia coli O157:H7. Epidemiological data shows that $8.3 \%$ of dairy and beef cattle may asymptomatically shed E. coli $\mathrm{O} 157: \mathrm{H} 7$ in their feces (Solomon, Yaron \& Matthews, 2002). One vehicle in which this pathogen is possibly transmitted is by contact of contaminated surface runoff including water contaminated with cattle feces (Solomon, Yaron \& Matthews, 2002). Aquaponics is a growing industry that combines the production of plants and fish using hydroponics and aquaculture (Timmons, \& Ebeling, 2007). The risk of fecal contamination in recirculating aquaponic systems that exclude warm-blooded animals and use potable water should be relatively low. Although the body temperature of fish (cold-blooded) is too low for these enteric pathogens to proliferate, fresh water fish (Tilapia in ponds), as well as their aquatic environment, can harbor food borne pathogens such as E. coli O157:H7 when contaminated with warm-blooded animal feces (Al-Harbi, 2003). The fish may even carry these enteric bacteria in 
1 their intestines for up to 7 days (Geldreich \& Clarke, 1966). Supporting evidence shows

2 coliforms within the gut of fish are not permanent flora, but instead related to the level of

3 contamination within their environment (Geldreich \& Clarke, 1966). Total and/or fecal coliform

4 counts are used as indicators for fecal contamination. A high level of coliform detection in water

5 provides evidence that there may be fecal contamination by a warm-blooded animal, indicating a

6 risk for enteric pathogens to be present. The detection of fecal contamination in aquaponic

7 operations has been predominantly seen in systems using poor quality source water and/or allow

8 for fecal inputs from domestic animals or wildlife (Fox, Tamaru, Hollyer, Castro, Fonseca, Jay-

9 Russell \& Low, 2012 ). Produce grown in systems such as these, may be at risk for enteric

10 pathogen contamination through internalization, despite efforts of surface sanitation.

E. coli $\mathrm{O} 157: \mathrm{H} 7$ has been shown to have several ways to internalize within the

12 tissue of produce (Gomes, Da Silva, Moreira, Castell-Perez, Ellis, \& Pendleton, 2009). For

13 example, evidence supports that E. coli $\mathrm{O} 157: \mathrm{H} 7$ cells can penetrate the stomata and junction

14 zones of lettuce leaves after being cut, as well as be transported into the plant through the root

15 system; this leaves post-harvest washing and surface sanitation methods ineffective on these cells

16 (Solomon, Yaron \& Matthews, 2002; Jablasone, Warriner \& Griffiths, 2005). In significant

17 relation, it also has been shown that E. coli $\mathrm{O} 157: \mathrm{H} 7$ can be transported through the roots of

18 hydroponically grown spinach and into the edible portions of the plant (Macarisin, Patel, \&

19 Sharma, 2014). This study investigates the possibility for internalization of Escherichia coli

20 O157:H7 through the roots of lettuce in a flow-through system that has shown to maintain fecal

21 contamination, as well as determine the efficacy of Ultraviolet light in water to inactivate

22 coliforms in water supplying nutrients to lettuce grown aquaponically on a floating raft. 
1

\section{MATERIALS AND METHODS}

\section{Aquaponic Facility}

A cold-water, spring fed aquaponic greenhouse, part of the aquaculture facility at Reymann Memorial Farm near Wardensville, WV, was used for the duration of this study. Spring water was collected as surface run-off and flowed by gravity through trout raceways before being pumped into the aquaponic greenhouse. The water supply to the aquaculture facility received runoff from cattle pastures allowing for fecal contamination from both cattle and wildlife. The water first flowed into a head-box within the building containing trout raceways. The head-box did not contain any fish and delivered the flow to raceways in parallel. Each raceway was $30 \mathrm{ft}$ long, $3 \mathrm{ft}$ wide with water $3 \mathrm{ft}$ deep supplied with a flow of about $662 \mathrm{~L} / \mathrm{min}$. Water flowed in parallel; each stream through a series of four raceways where Rainbow Trout (Oncorhynchus mykiss) were housed and fed. Each of the eight raceways had a quiescent zone from which fish were excluded and solid waste would settle out. Periodically accrued solid waste would be removed from these quiescent zones. Water leaving the last raceways flowed into a tail-box and out of the facility by being pumped into the aquaponic greenhouse without additional treatment (Figure 7A).

The greenhouse housed lined plywood structures, each with 3 aquaponic channels at waist-level, or about $3 \mathrm{ft}$ off the ground (Figure 7B). Each channel was approximately $39 \mathrm{~cm}$ wide, and $238 \mathrm{~cm}$ long and held water at a depth of 8 inches. Water entered (Inlet) each channel through a capped 1 inch PVC pipe with a 3/8 inch hole controlling flow volume to deliver approximately $7.6 \mathrm{~L} / \mathrm{min}$ to each channel. Water drained from each channel through a 2 inch 
1 standpipe near the end wall. Each channel was scrubbed clean and disinfected with chlorine prior

2 to the experiment.

$3 \quad$ Lettuce (Latuca sativa 'Red Sails') was grown in polystyrene Speedling® trays with 128

4 cells/tray to which vermiculite was added as a growing medium. Each tray was approximately 34

$5 \mathrm{~cm}$ wide and $67 \mathrm{~cm}$ long and each cell was 4.45 sq.cm and 6.35 sq.cm deep. Three trays floated

6 end to end on the water surface of each aquaponic channel between the inlet and the drain. Seeds

7 were sown directly on to the vermiculite surface of the trays using a vacuum seeder. Eight

8 channels were used in this experiment with the $9^{\text {th }}$ channel being used for overflow. Four of the

9 eight channels were randomly selected to receive UV-treated water. Statistical analysis were

10 done to find the mean Log reduction in total coliforms between treated and untreated water, as

11 well as the mean difference between the head-box and tail-box using Tukey's HSD multiple

12 comparison method.

\section{UV light system}

Of the 8 channels containing lettuce, 4 were randomly selected to receive UV light

16 treatment in which the water would first pass through a UV light system before reaching the

17 channel. The UV system used, a custom modified version of model COM480HO-2U, was composed of an 80 watt bulb in a 54" X 6.63" cylindrical vessel purchased from Emperor

19 Aquatics in Pottstown, PA. This UV system was particularly chosen for this experiment to successfully inactivate coliforms while still leaving a detectible level to enumerate. The

21 manufacturer specifications for this system are a dose of $180 \mathrm{~mJ} / \mathrm{cm}^{2}$ at $26 \mathrm{~L} / \mathrm{min}$ and $30 \mathrm{~mJ} / \mathrm{cm}^{2}$

22 at $170 \mathrm{~L} / \mathrm{min}$ in water with $90-95 \%$ transmittance $(\mathrm{T})$. Water passing through the UV system had 23 a mean transmittance of $96.64 \%$ and a flow-rate of $48.3 \mathrm{~L} / \mathrm{min}$. 


\section{Water sample collection and inoculation}

Water was sampled every 2 weeks over a 6 week interval, beginning on week 0 (the day

4 after seeds were planted). Samples were taken at the head-box, tail-box, the inlet of each

5 aquaponic channel (Channel in), and at the drain of each channel (Channel out). Glass bottles

6 used for collecting samples were autoclaved and sealed before use. Water samples collected from

7 the head-box were directly filled by placing the bottle underneath the head-box discharge. This

8 was done the same for water flowing into the tail-box. Water collected from the channel inlet

9 was collected by placing the bottles directly beneath the spout. Lastly, water collected near the

10 channel drain was taken up by using a $25 \mathrm{ml}$ sterile pipette, using a new pipette for each channel.

11 Water was collected in an upstream manner to prevent any direct contamination or disturbance to

12 the samples. Samples were placed in an ice-filled cooler to be transported to the lab and

13 refrigerated overnight.

Sample bottles were tipped back and forth 5 times to ensure even distribution. They were

15 then platted on 3-M Petrifilm ${ }^{\mathrm{TM}}$ EC (E.coli/coliform plate) by dispensing $1 \mathrm{ml}$ onto the plate

16 using $1000 \mu \mathrm{l}$ sterile micropipettes according to the manufacture's standard methods. The 3-M

17 petrifilm manufacturer specifies that red colonies represent coliforms whereas blue colonies

18 represent $E$. coli with the exception of $E$. coli $\mathrm{O} 157: \mathrm{H} 7$ which appear as red colonies. Plates were

19 incubated at $35^{\circ} \mathrm{C}$ for $48 \mathrm{~h}$ before enumerating. Immediately following inoculation of each

20 sample on 3M-Petrifilm, samples were prepared to be plated on M-endo agar.

Using a vacuum, samples for M-endo agar were first filtered through sterile NEO-GRID

22 membrane filters with a pore size of $0.45 \mu \mathrm{m} .1 \mathrm{~L}$ of all UV treated samples for inflowing water

23 to the channels was poured directly through the membrane filter; the large volume was to 
1 accommodate for the low coliform/E. coli population present. $1 \mathrm{ml}$ of all other samples were

2 dispensed into $99 \mathrm{ml}$ of phosphate buffer and poured through the filter to ensure an even

3 distribution. These samples were first tilted back and forth 5 times before being poured into the

4 filter system. Using sterile forceps, filters were placed in a petri dish containing M-endo agar

5 under a bio-safety cabinet. Plates were incubated at $35^{\circ} \mathrm{C}$ for $48 \mathrm{~h}$ to be enumerated.

7 Confirmation tests

Confirmation tests were done on samples from week 6; this was done to both 3-M

9 petrifilm and M-endo agar plates by selecting 6 plates of each. Due to the presence of 2

10 distinguishable types of colony growths on each media, only plates with both types were chosen.

113 colonies of each type were randomly chosen from different quadrants of the plate to be

12 confirmed. Colonies were sampled using sterile wooden applicator sticks; this was done within a

13 bio-safety cabinet by touching the end of the applicator stick to a chosen colony. The applicator

14 stick was then dropped in a test tube of Lauryl Tryptose Broth (LTB) containing a Durham tube.

15 LTB tubes were then incubated at $35^{\circ} \mathrm{C}$ for $48 \mathrm{~h}$ to check for gas production according to

16 standard methods.

17

\section{Sampling of lettuce and detection of internalization}

Lettuce samples were taken from the center of each channel to limit the risk of

20 contamination through the splashing of water from other channels. Samples were cut

21 approximately $1 \mathrm{~cm}$ above the vermiculite substrate using scissors previously sterilized with $70 \%$

22 ethanol. Scissors were cleaned with ethanol between sampling of each channel and allowed to 
1 air-dry. Lettuce from each channel was placed in a sterile plastic bag and was weighed out to 6

2 grams. Bags were sealed shut and placed on ice to be transported back to the lab for analysis. Under UV light, lettuce was dipped and swirled in a solution containing deionized water,

$4 \quad 10 \%$ bleach, and 3 drops of dish soap for approximately 10 seconds. They were then dipped

5 similarly in four containers of deionized water, successively. UV light was turned off and lettuce

6 was minced with a sterile scalpel blade and placed in a $50 \mathrm{ml}$ sterile plastic tube containing $10 \mathrm{ml}$

7 of phosphate buffer. Samples were then homogenized beginning with samples grown in UV

8 treated water to reduce the risk of cross contamination. Homogenizer was cleaned using $70 \%$

9 ethanol and rinsed in deionized water between each sample. $800 \mu$ l of each sample was placed on

10 large petri dishes $(150 \times 15 \mathrm{~mm})$ containing M-endo agar using a micro pipette. Samples were

11 distributed using a large stainless steel cell spreader while spinning the petri dish on a petri dish

12 turntable. The cell spreader was dipped in ethanol, flamed, and allowed to cool between plating.

13 Plates were incubated at $35^{\circ} \mathrm{C}$ for $48 \mathrm{~h}$ to be enumerated.

15 testing as previously done with the water samples. Entire agar medium was then swabbed with a

16 sterile cotton swab and placed in LTB to check for any sign of coliform bacteria.

\section{Statistical analysis}

All statistical analyses were done using SAS JMP 11 software. Data for 3-M Petrifilm were standardized to a volume of 1 Liter before analyzing. Comparison of means, including

21 mean Log reduction from treatment and all p-values, were done using Tukey's HSD multiple 22 comparison method. 


\section{RESULTS AND DISCUSSION}

Water sample analysis on 3-M Petrifilm

4

5

6

Two distinguishable types of colonies were evident on the 3-M petrifilm. Both large, red colonies (expected) and small, light-red colonies were distinguished. Over the duration of the study, there was an increase in bacterial load (Figure 1). This increase was seen for large colonies in the UV treated water entering the channels (channel in), as well as for small colonies in both the UV treated water entering (channel in) and leaving (channel out) the channels. By week 6 , the amount of small colonies present in the UV treated water entering and leaving the channels had a higher mean than that of the corresponding untreated water (Figure 1). This phenomenon is most likely related to accumulation of particles in the pipes and channels or to the resulting biofilm formation.

The mean difference between treated and untreated water for large colonies was significant for both water entering and leaving the channels $\left(\mathrm{p}<0.0001^{*}\right)$ (Figure 2A, Table 1). As for small colonies, the mean difference was not significant for water going into or leaving the channels (Figure 2B, Table 1). A much greater variation within the treated water samples can be seen with the small colonies as compared to the large colonies (Figures 3A \& 3B). Due to the observed properties of higher UV resistance seen in these smaller colonies, as compared to the expected larger colonies, there is evidence that the majority of these smaller colonies are not coliform bacteria. As expected, there was no significant difference between water samples taken from the head-box and the tail-box regarding both large and small colonies. This confirms that the fish did not significantly contribute to the presence of either colonies in the water. 
Confirmation tests that were done for randomly chosen small and large colonies gave a

2

percentage much lower than expected. For large colonies, only $22.22 \%$ of the randomly chosen colonies produced gas in the LTB to be confirmed as true coliforms; whereas, the smaller colonies had a much lower confirmation of $5.56 \%$ as true coliforms. Once again, this indicates that the majority of these colonies are not colifoms.

The 3-M petrifilm was also used to distinguish the presence of $E$. coli resulting in a blue colony formation. The mean count for $E$. coli present in both the head-box and tail-box was 1 $\mathrm{CFU} / \mathrm{ml}$. Of the untreated water samples taken during the duration of the study, 7 out of 16 samples going into the channels tested positive for $E$. coli as high as $5 \mathrm{CFU} / \mathrm{ml}$, and 8 out of 16 samples leaving the channel tested positive for up to $4 \mathrm{CFU} / \mathrm{ml}$. Only 1 out of 32 samples of UV treated water showed $E$. coli presence at $2 \mathrm{CFU} / \mathrm{ml}$ in the water leaving the channel on week 0.

\section{Water sample analysis on M-endo agar}

According to standard methods, green colonies represent coliforms on M-endo agar with the exception of false-positive green colonies and false-negative red colonies. Both green and red colonies were distinguished and enumerated separately. All green and red colony counts for water going into the channels stayed relatively consistent throughout the duration of the study. However, red colonies in the treated water leaving the channels increased over the 6 week duration and were slightly higher than that of the untreated water (Figure 4), resembling similar characteristics to the small colonies seen on the 3-M petrifilm (Figure 1).

The mean reduction from UV treatment was significant for green colonies entering and leaving the channels $(\mathrm{p}<0.0001)$ (Figure 5A, Table 2). The mean reduction in red colonies only showed to be significant for water going into the channels $\left(\mathrm{p}<0.0001^{*}\right)$ and was not significant 
1 for water leaving the channels $(\mathrm{p}=0.053)$ (Figure 5B, Table 2). This shows further evidence that

2 the majority of these red colonies are not coliforms. The mean difference between the head-box

3 and tail-box was insignificant for both green and red colonies ( $p=1.0$ and $p=0.98$, respectively)

4 (Figures 5A \& 5B, Table 2). A much greater variation within the treated water samples can be

5 seen with the red colonies as compared to the green colonies (Figures 6A \& 6B).

6 Confirmation tests done for randomly chosen green and red colonies gave a much higher

7 confirmation than that of the 3-M petrifilm, while still lower than expected. For green colonies,

$847 \%$ of the randomly chosen colonies produced gas in the LTB to be confirmed as true

9 coliforms. For the red colonies, $30 \%$ tested positive for true coliforms. When calculating the total

10 amount of coliforms based off of green colonies detected on m-endo agar, adjusting it by the

11 percentage confirmed, and standardizing it to CFU/100ml, it was found that untreated water

12 contained a mean of $8.39 \times 10^{2} \mathrm{CFU} / \mathrm{ml}$ of true coliforms while treated water entering and

13 leaving the channels had a mean of $1.89 \times 10^{-1}$ and $9.92 \times 10^{1} \mathrm{CFU} / \mathrm{ml}$, respectfully.

14 These results demonstrate the effectiveness of UV-radiation in aquaponic systems

15 receiving mixed water sources. The UV system used in this study was specifically chosen to

16 inactivate total coliforms yet still leave enough remaining in the water to enumerate. The UV

17 system recommended by Emperor Aquatics for appropriate inactivation of coliforms had a

18 stronger out-put of UV-dosage.

20 Analysis of lettuce

21

During preliminary studies, filtration of lettuce particles through a series of sieves was

22 unsuccessful. When homogenized lettuce samples were directly plated, coliforms were easily

23 identified. However, the direct inoculation of the homogenized lettuce in this experiment lead to 
1 excessive debris on the agar, as well as a discoloration of the applied sample. This dark-red and

2 black discoloration may have been bacterial growth at large concentrations. Some individual

3 black colonies were seen and 3 from each plate were sampled for confirmation; the color of these

4 colonies was most likely a result of the decaying lettuce debris. The plates were then swabbed in

5 hopes that if any coliforms were present, it would show up in the confirmation tests. None of the

6 colonies or swabs tested positive in the confirmation tests. No detection of internalization was

7 found; although, techniques in this experiment could be improved to eliminate the lettuce debris

8 from the samples in order to increase the sensitivity of the test. This can be done using filter bags

9 in a bag mixer and/or centrifugation of the samples.

The resulting high levels of total coliforms and E. coli found in the water indicate fecal

11 contamination of warm-blooded animals (pathogenicity of E. coli strands found was not

12 determined). Despite evidence of internalization with coliforms such as E. coli O157:H7, and

13 other enteric pathogens (Salmonella spp.) in studies that inoculated growing substrates (soil,

14 water, and/or manure) of leafy greens, this study did not provide supporting evidence (Solomon,

15 Yaron \& Matthews, 2002; Macarisin, Patel \& Sharma, 2014).

\section{CONCLUSIONS}

With the exception of the small colonies, a significant reduction was observed with all other types of colonies in treated water going into the channels tested on 3-M petrifilm. Only

20 green colonies from M-endo agar and large colonies from 3-M petrifilm showed a significant

21 reduction from UV light in the water leaving the channels. Despite using a UV light system

22 below manufacturer recommendations for the given flow rate and turbidity of the water, the

23 system still showed to be very effective in coliform and E. coli reduction. The system was not 
1 cleaned during the study in order to limit disturbances of particles inside the unit or the

2 plumbing. Cleaning the system between samples may have created large spikes in coliform

3 concentrations seen. This was also done to monitor the effectiveness of the system over time

4 without intervention. Confirmation tests showed that the large colonies from the 3-M Petrifilm

5 resembled true coliforms most accurately and that a 3-Log reduction over the course of 6 weeks

6 can be seen in a system such as this without any maintenance to the UV system. Though no

7 internalization was seen with the lettuce, techniques could be improved with how the lettuce was

8 sampled. Internalization may also be a phenomenon only seen in specific circumstances.

9 However, UV light irradiation of coliforms in water does show to be an effective treatment;

10 given the proper system and adequate maintenance.

\section{REFERENCES}

Al-Harbi. (2003). Faecal coliforms in pond water, sediments and hybrid tilapia Oreochromis niloticus x Oreochromis aureus in Saudi Arabia. Aquaculture !Research 34:517-524.

Deering, A. J., Mauer, L. J., \& Pruitt, R. E. (2012). Internalization of E. coli O157:H7 and salmonella spp. in plants: A review. Food Research International, 45(2), 567-575. doi:http://dx.doi.org.www.libproxy.wvu.edu/10.1016/j.foodres.2011.06.058

Fox, B. K., Tamaru, C. S., Hollyer, J., Castro, L. F., Fonseca, J. M., Jay-Russell, M., \& Low, T. (2012). A preliminary study of microbial water quality related to food safety in recirculating aquaponic fish and vegetable production systems. College of Tropical Agriculture and Human Resources, University of Hawaii at Manoa. Food Safety and Technology.

Geldreich, E. E., \& Clarke, N. A. (1966). Bacterial pollution indicators in the intestinal tract of 
freshwater fish. Applied microbiology, 14(3), 429-437.

Gomes, C., Da Silva, P., Moreira, R. G., Castell-Perez, E., Ellis, E. A., \& Pendleton, M. (2009). Understanding E. coli internalization in lettuce leaves for optimization of irradiation treatment. International Journal of Food Microbiology, 135(3), 238-247. doi:http://dx.doi.org.www.libproxy.wvu.edu/10.1016/j.ijfoodmicro.2009.08.026

Jablasone, J., Warriner, K., \& Griffiths, M. (2005). Interactions of escherichia coli O157:H7, salmonella typhimurium and listeria monocytogenes plants cultivated in a gnotobiotic system. International Journal of Food Microbiology, 99(1), 7-18. doi:http://dx.doi.org.www.libproxy.wvu.edu/10.1016/j.ijfoodmicro.2004.06.011

Macarisin, D., Patel, J., \& Sharma, V. K. (2014). Role of curli and plant cultivation conditions on escherichia coli O157:H7 internalization into spinach grown on hydroponics and in soil. International Journal of Food Microbiology, 173(0), 48-53. doi:http://dx.doi.org.www.libproxy.wvu.edu/10.1016/j.ijfoodmicro.2013.12.004

Rangel, J. M., Sparling, P. H., Crowe, C., Griffin, P. M., \& Swerdlow, D. L. (2005). Epidemiology of Escherichia coli O157:H7 Outbreaks, United States, 1982-2002. Emerging Infectious Diseases, 11(4), 603-609. doi:10.3201/eid1104.040739

Sivapalasingam, S., Friedman, C. R., Cohen, L., \& Tauxe, R. V. (2004). Fresh produce: a growing cause of outbreaks of foodborne illness in the United States, 1973 through 1997.

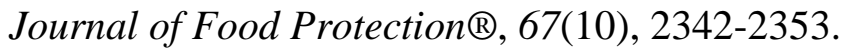

Solomon, E. B., Yaron, S., \& Matthews, K. R. (2002). Transmission of Escherichia coli O157:H7 from contaminated manure and irrigation water to lettuce plant tissue and its subsequent internalization. Applied and Environmental Microbiology, 68(1), 397-400. Retrieved from http://search.ebscohost.com.www.libproxy.wvu.edu/login.aspx?direct=true \&db=ffh\&AN $=2002-05-J q 1093 \&$ site=ehost-live 
1

2 Timmons, M., \& Ebeling, J. (2007). Aquaponics: Integrating Fish and Plant Culture. In 3 Recirculating aquaculture (2nd ed., p. 807). Ithaca: Cayuga Aqua Ventures.

4

5

6

7

8

9 
1 Figure 1. Detected small and large colonies (Log CFU/ml) on 3-M petrifilm over 6 weeks in both UV treated and untreated water for

2 water flowing into and leaving the channels (channel in \& channel out). Lines represent geometric means over time.

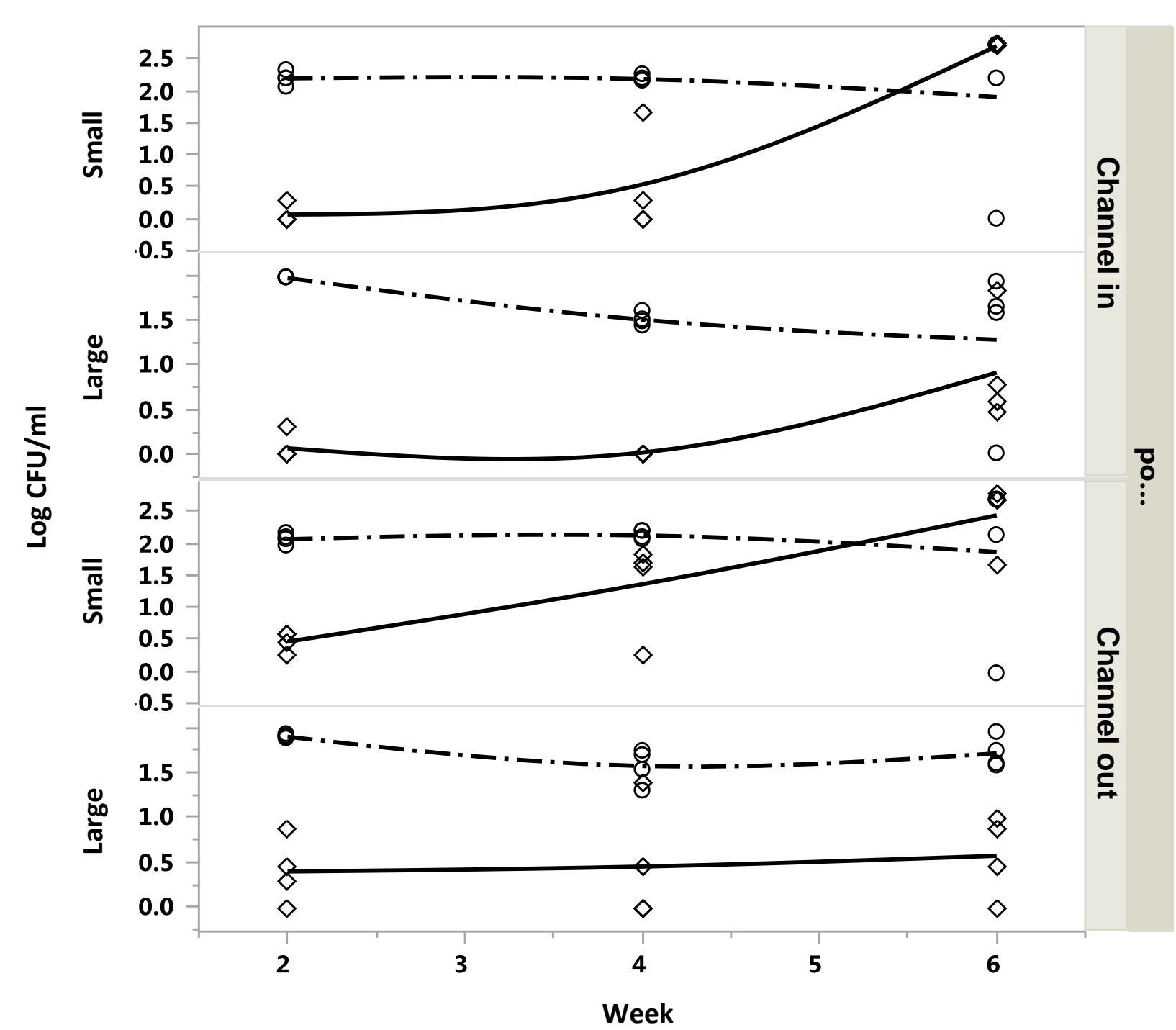

$-\cdot-$ Untreated

- Untreated

- UV Treated

$\diamond$ UV Treated 
1 Figure 2A. Mean Log count + (SE) for large colonies on 3-M petrifilm (CFU/ml) at various points. Different letters on the top of data 2 bars indicate significant differences $(\mathrm{p}<0.0001)$.

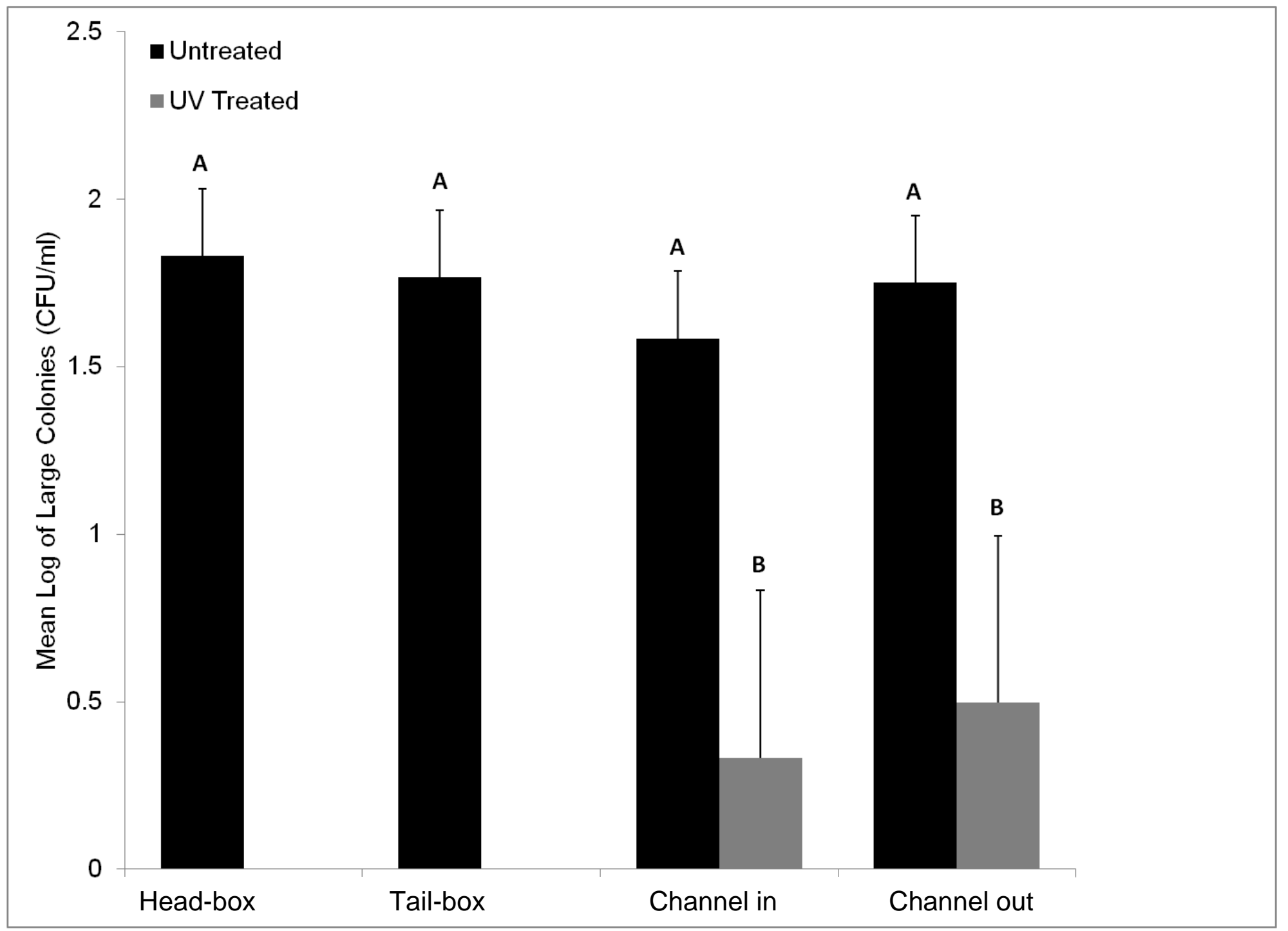


1 Figure 2B. Mean Log count + SE for small colonies on 3-M petrifilm (CFU/ml) at various points. Different letters on the top of data

2 bars indicate significant differences $(\mathrm{p}<0.0001)$.

3

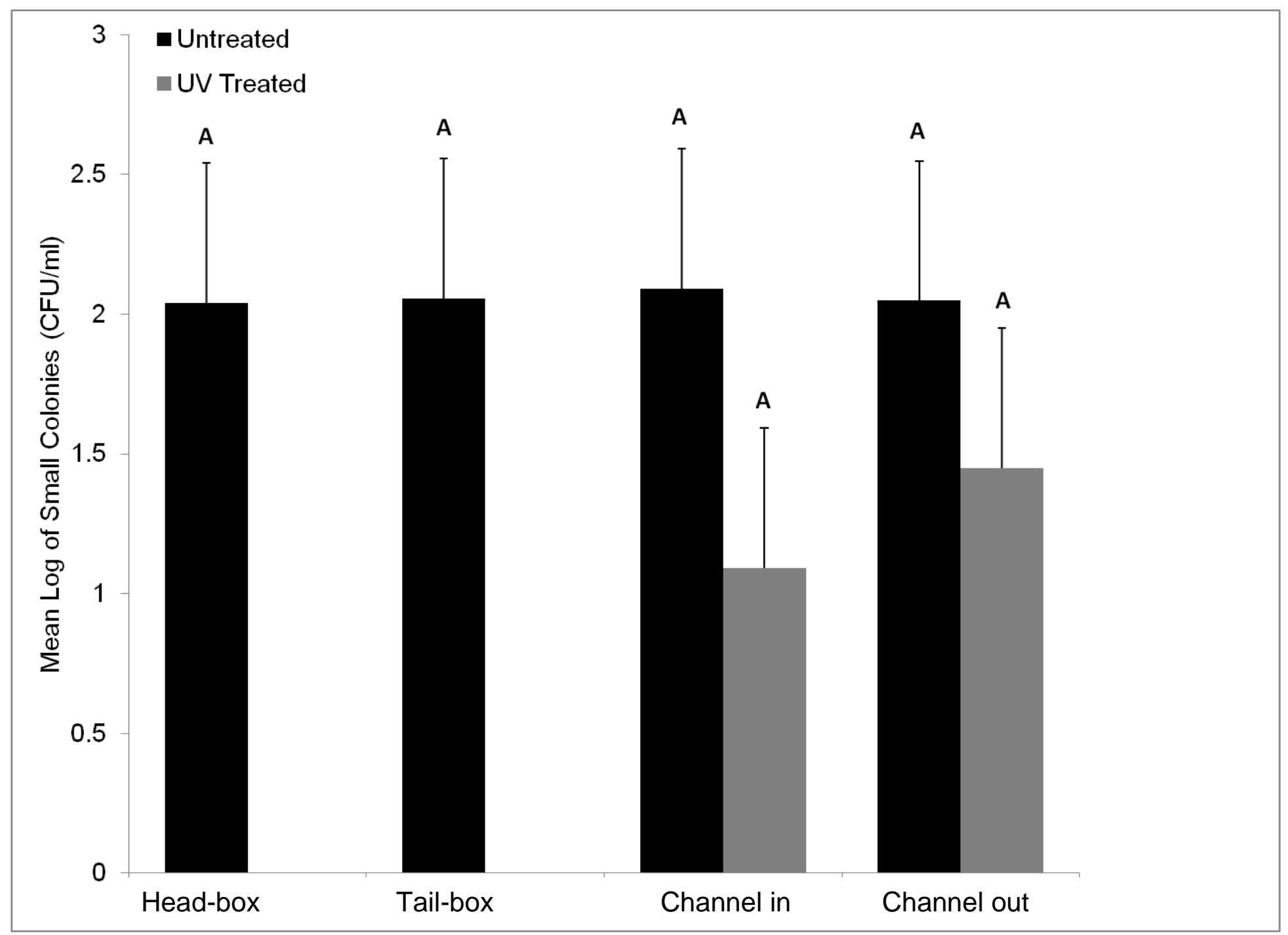


Figure 3A. Represents variance of large colonies seen on 3-M petrifilm within different points of the location where water was sampled (Log CFU/ml). Line within the box represens the median, the upper and lower quadrants represent $75^{\text {th }}$ and $25^{\text {th }}$ percentile, respectively, while the whiskers of the box represent maximum and minimum data points.

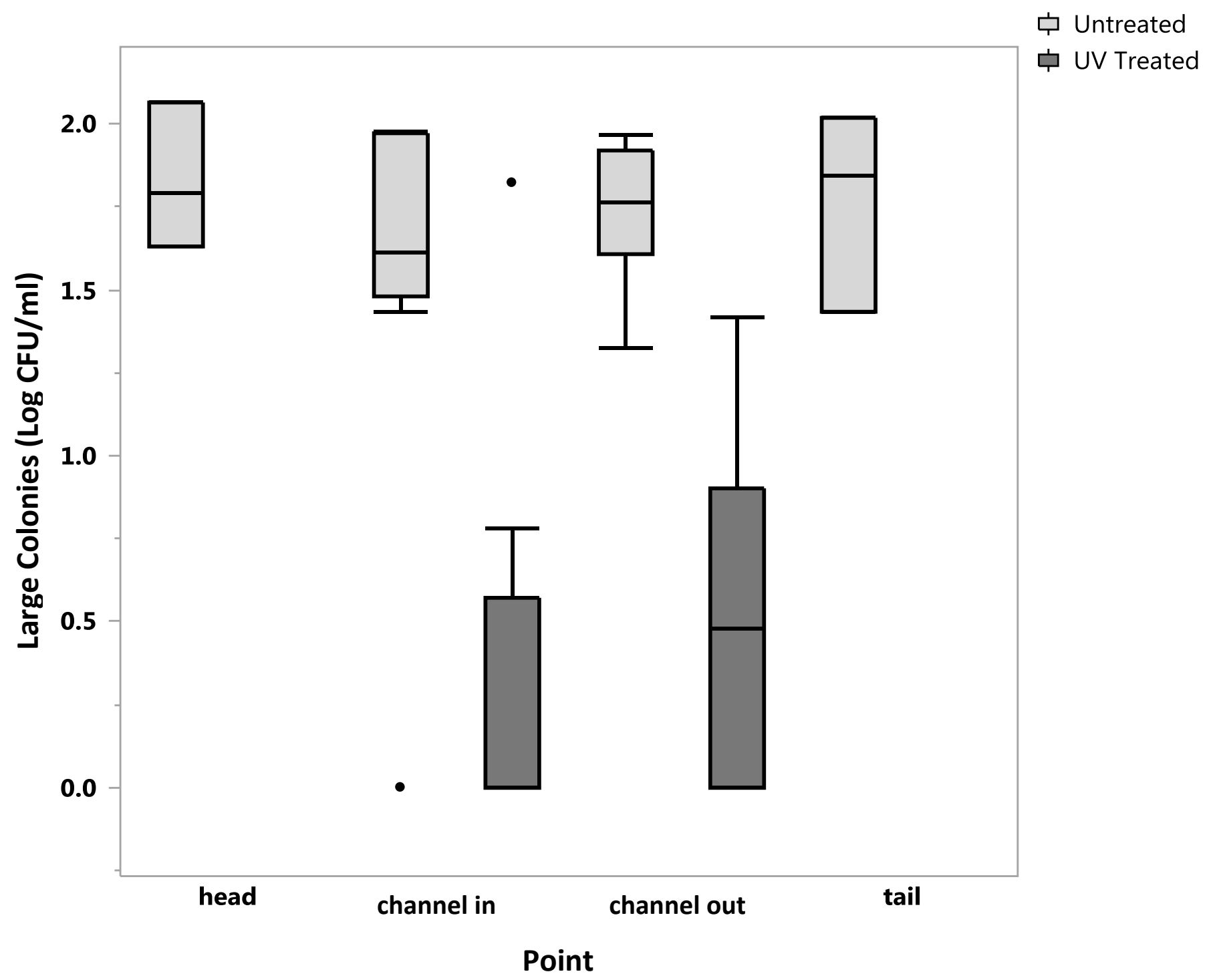


Figure 3B. Represents variance of small colonies seen on 3-M petrifilm within different points of the location where water was sampled $(\mathrm{CFU} / \mathrm{ml})$. Line within the box represens the median, the upper and lower quadrants represent $75^{\text {th }}$ and $25^{\text {th }}$ percentile, respectively, while the whiskers of the box represent maximum and minimum data points.

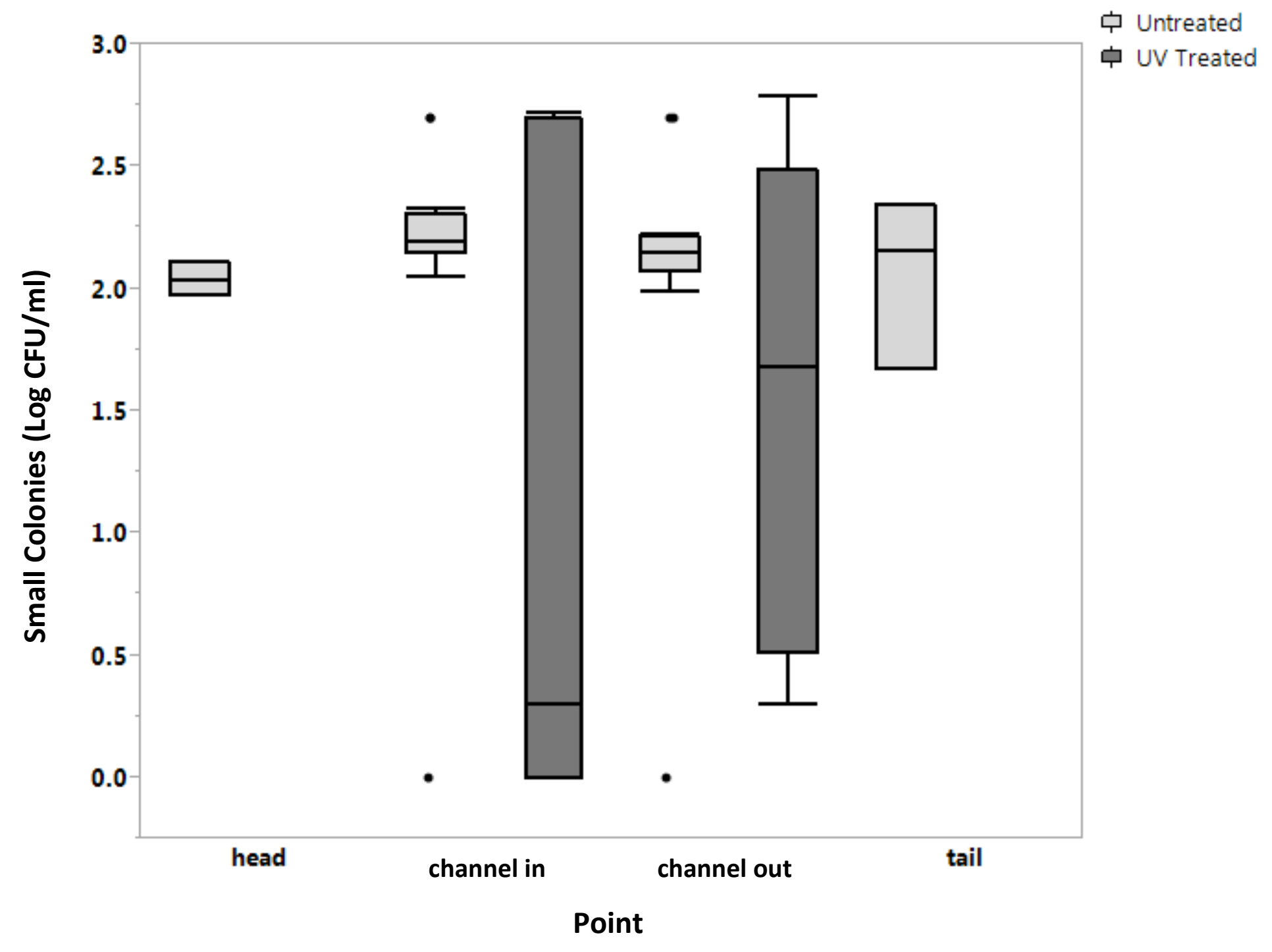


1 Figure 4. Detected green and red colonies (Log CFU/L) on M-endo agar over 6 weeks in both UV treated and untreated water for

2 water flowing into and leaving the channels (channel in \& channel out). Line representative of geometric mean.

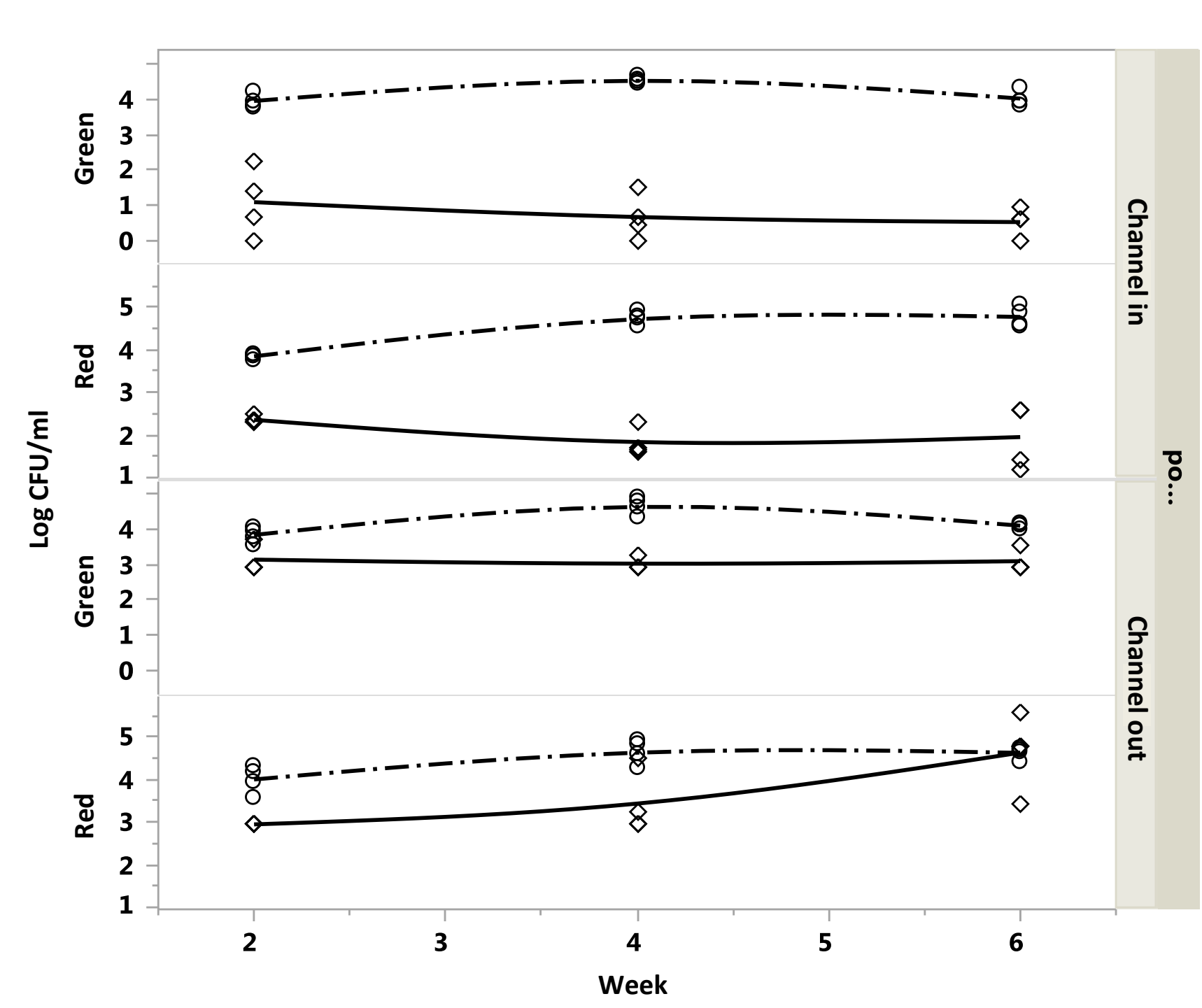

-- - Untreated

- Untreated

- UV Treated

$\diamond$ UV Treated 
1 Figure 5A. Mean Log count + SE for green colonies on M-endo agar (CFU/L) at various points. Different letters on the top of data 2 bars indicate significant differences ( $\mathrm{p}<0.0001)$.




1 Figure 5B. Mean Log count + SE for red colonies on M- endo agar (CFU/L) at various points. Different letters on the top of data bars 2 indicate significant differences $(\mathrm{p}<0.0001)$.

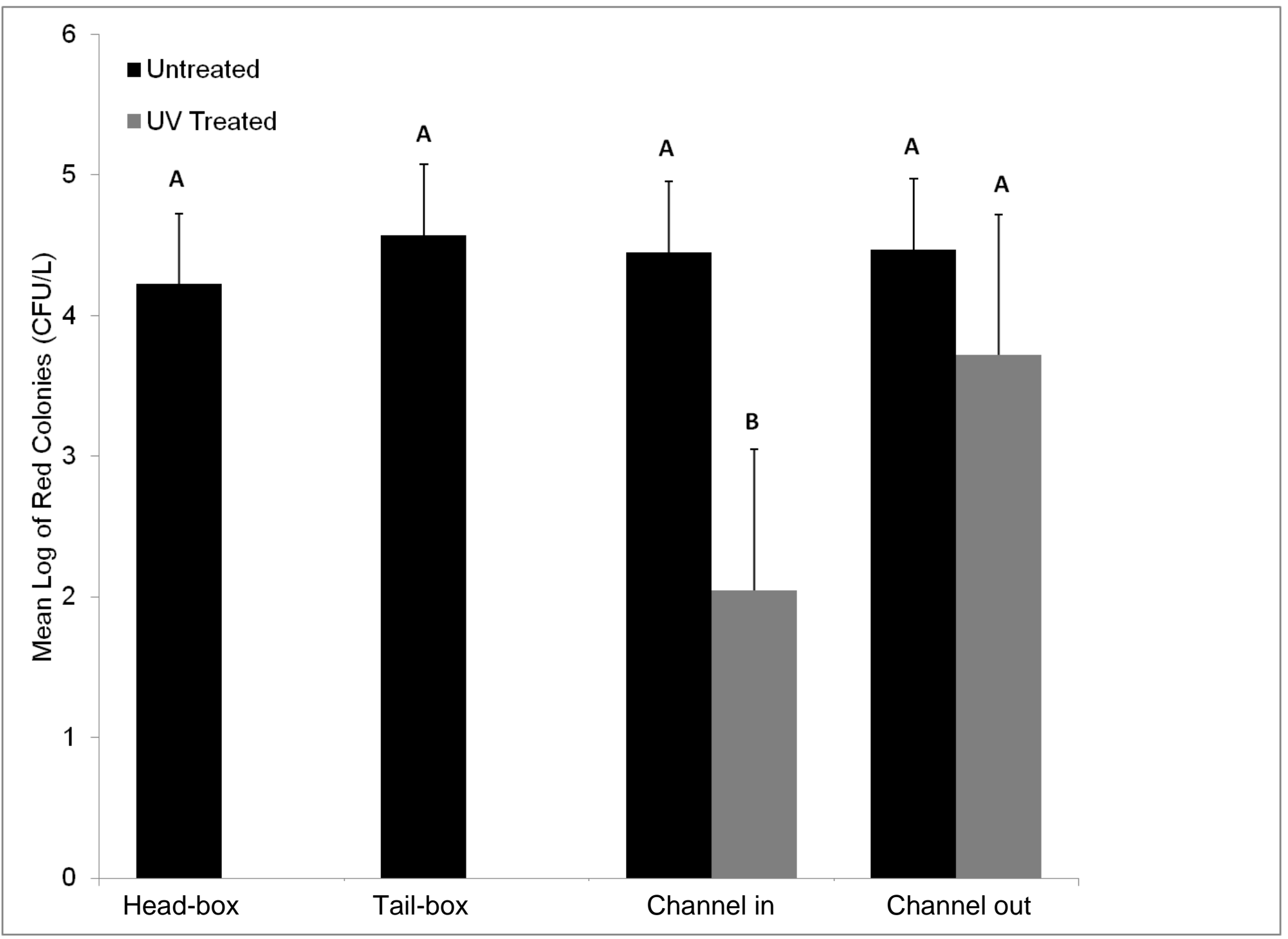


Figure 6A. Represents variance of green colonies seen on M-endo agar within different points of the location where water was sampled (Log CFU/ml). Line within the box represens the median, the upper and lower quadrants represent $75^{\text {th }}$ and $25^{\text {th }}$ percentile, respectively, while the whiskers of the box represent maximum and minimum data points.

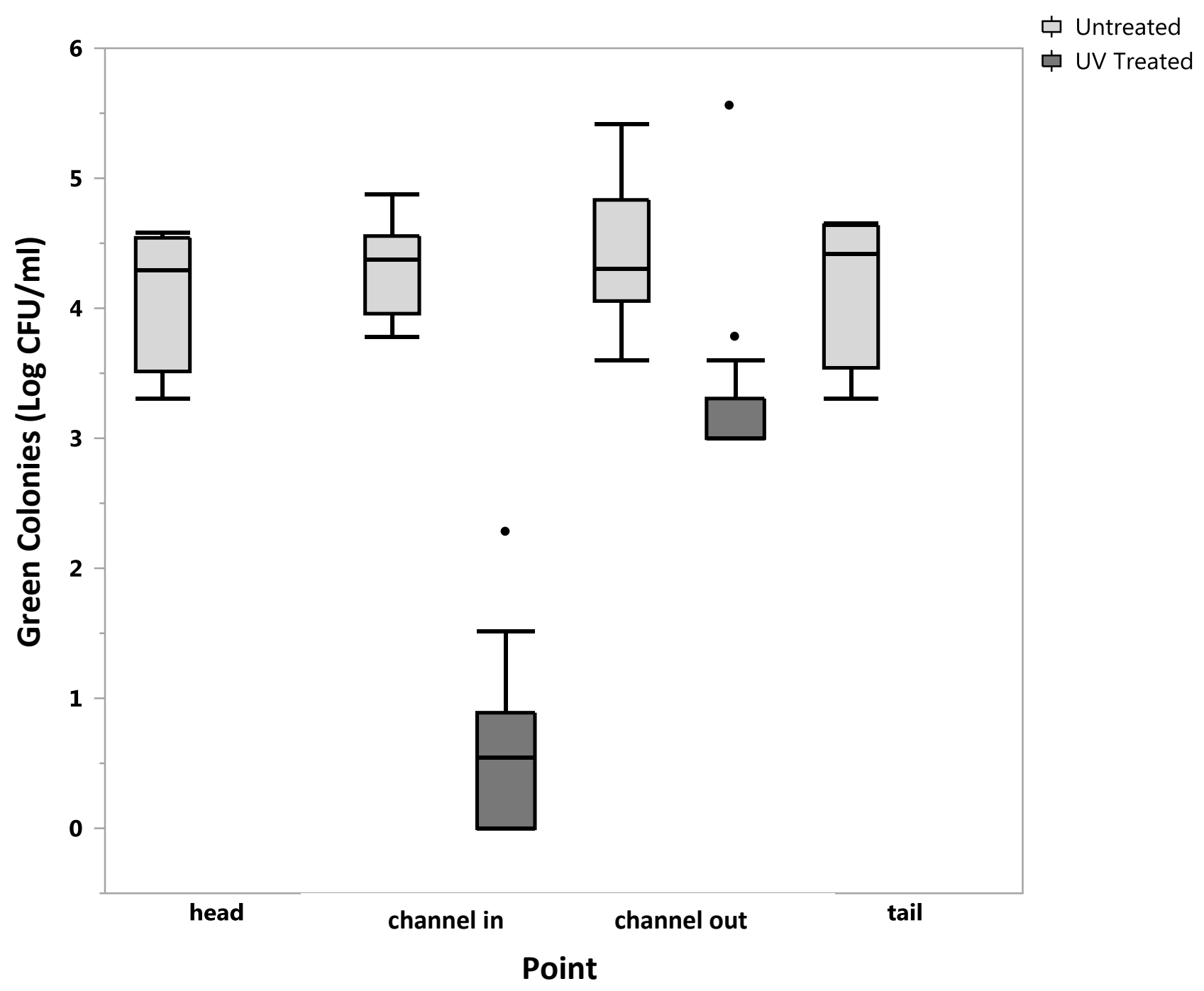


2 Figure 6B. Represents variance of red colonies seen on M-endo agar within different points of the location where water was sampled $3(\log \mathrm{CFU} / \mathrm{ml})$. Line within the box represens the median, the upper and lower quadrants represent $75^{\text {th }}$ and $25^{\text {th }}$ percentile, 4 respectively, while the whiskers of the box represent maximum and minimum data points.

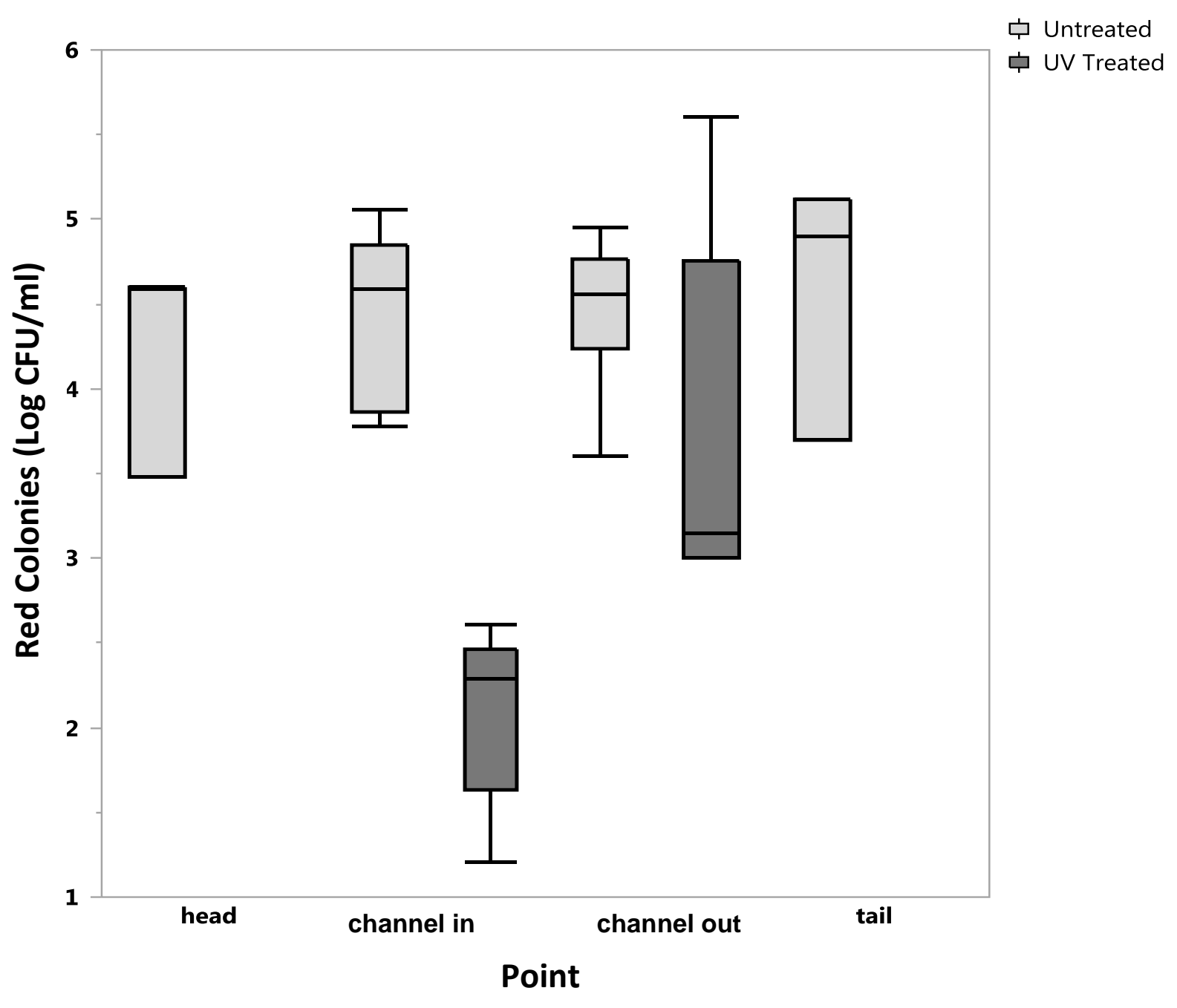


1 Figure 7A: Representative diagram of aquaculture facility.

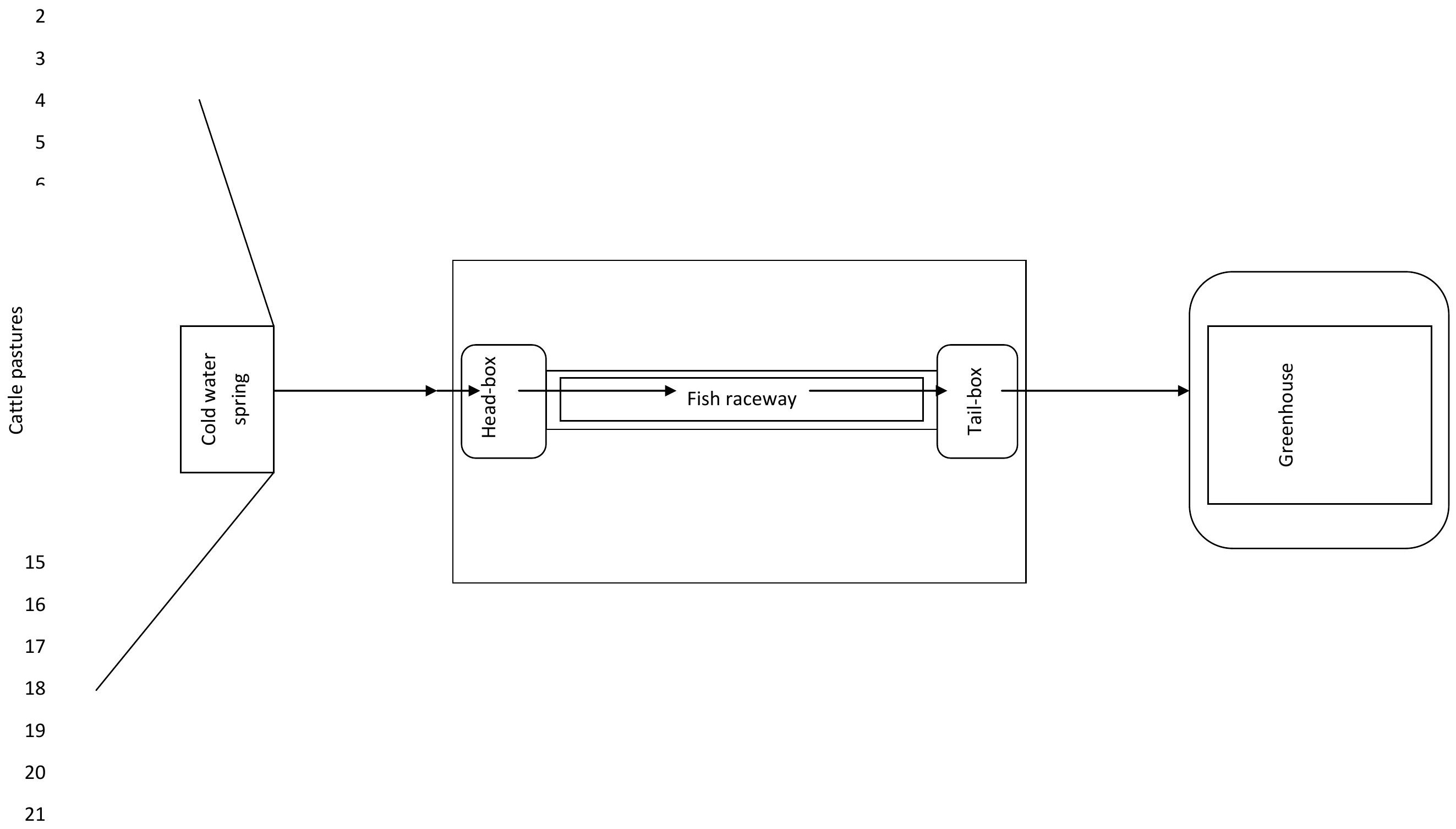


1 Figure 7B: Representative diagram of aquaculture greenhouse.

2

3

4

5

6

7

8

9



19

20 
1 Table 1. Mean Log difference \pm standard deviation between treated and untreated water at different sampling points for colonies

2 found on 3-M petrifilm. Given p-values found using Tukeys HSD.

3

\begin{tabular}{ccccc} 
& \multicolumn{4}{c}{ Mean Log Difference of Colonies (CFU/ml) } \\
\cline { 2 - 5 } Point & Large & p-Value & Small & p-Value \\
\hline Channel in & $1.25 \pm 0.22$ & $<0.0001$ & $1.0 \pm 0.42$ & 0.0896 \\
Channel out & $1.25 \pm 0.15$ & $<0.0001$ & $0.60 \pm 0.34$ & 0.585 \\
Head \& Tail & $0.06 \pm 0.22$ & 1.0 & $0.02 \pm 0.2$ & 1.0
\end{tabular}


1 Table 2. Mean Log difference \pm standard deviation between treated and untreated water at different sampling points for colonies 2 found on M-endo agar. Given p-values found using Tukeys HSD.

Mean Log Difference of Colonies (CFU/ml)

\begin{tabular}{ccccc} 
Point & Green & p-Value & Red & $p$-Value \\
\hline Channel in & $3.68 \pm 0.19$ & $<0.0001$ & $2.41 \pm 0.20$ & $<0.0001$ \\
Channel out & $1.09 \pm 0.20$ & $<0.0001$ & $0.75 \pm 0.30$ & 0.0533 \\
Head \& Tail & $0.08 \pm 0.42$ & 1.0 & $0.35 \pm 0.58$ & 1.0
\end{tabular}


5 CHAPTER 2: Internalization of E. coli O157:H7 in Hydroponically Grown Lettuce with Randomized Injury Afflicted on Roots

Matthew J. Moriarty

8

Division of Animal and Nutritional Sciences, West Virginia University, Morgantown, West Virginia, 26506

17 


\section{INTRODUCTION}

The frequency in which Escherichia coli O157:H7 has been isolated from fresh produce has increased in recent years (Solomon, Yaron \& Matthews, 2002). Less than 1\% of reported food borne outbreaks with known food sources was linked to fresh produce in the 1970's. That number has risen to over 6\% in the 1990's (Deering, Mauer \& Pruitt, 2012). Despite safe agricultural and postharvest practices, there has also been an increase in food borne outbreaks of E. coli O157:H7 associated with leafy greens (Macarisin, Patel \& Sharma, 2014). Of specific interest, literature (Solomon, Yaron \& Matthews, 2002) shows that it is possible for E. coli O157:H7 to have the ability to internalize in the edible portions of fresh produce. Research has shown E. coli $\mathrm{O} 157: \mathrm{H} 7$ to internalize in lettuce plant tissue through transmission from contaminated manure and irrigation water in soil grown plants (Solomon, Yaron \& Matthews, 2002). Similarly, it has been seen with Salmonella enterica in tomato plants (Zheng, Allard, Reynolds, Millner, Arce, Blodgett \& Brown, 2013). In hydroponically grown spinach, E. coli O157:H7 reportedly used plants' roots as the principle route of internalization (Koseki, Mizuno \& Yamamoto, 2011). Internalization of enteric pathogens in produce is of particular concern as it may pose a safety risk in which washing and surface sanitation methods are unlikely to be effective (Gomes, Da Silva, Moreira, Castell-Perez, Ellis \& Pendleton, 2009).

Hydroponics and aquaponics are both growing industries. Hydroponics is the act of growing plants in a nutrient solution root medium (U.S. Department of Agriculture, 2014); whereas, aquaponics is the combination of plant and fish production using hydroponics and aquaculture (Timmons, \& Ebeling, 2007). The FDA has proposed guidelines for good agricultural practices (GAPs) for all produce farms to follow. These GAPs include worker hygiene, wildlife and domestic animal exclusion methods, and prevention of contact between the 
1 edible portion of the plant and the culture water. Some commercial produce buyers are starting to

2 require for their supplying farms to undergo third-party audits to minimize the chance of a food

3 borne outbreak. However, this is sometimes arbitrary when these guidelines do not differentiate

4 between the practices of soil and soilless grown crops (Fox, Tamaru, Hollyer, Castro, Fonseca,

5 Jay-Russell \& Low, 2012). Although freshwater fish can harbor enteric pathogens commonly

6 found in warm-blooded animals, their micro-flora is a reflection of their aquatic environment

7 (Al-Harbi, 2003; Fox, Tamaru, Hollyer, Castro, Fonseca, Jay-Russell \& Low, 2012 ). However,

8 some systems may have fecal contamination due to the origin of their source water and/or fecal

9 contamination from wildlife or domestic animals (Fox, Tamaru, Hollyer, Castro, Fonseca, Jay-

10 Russell \& Low, 2012 ).

11 One risk factor associated with fecal contamination of water is the ability for E. coli

12 O157:H7 to survive for extended periods. A study which inoculated Bottled spring and mineral

13 waters with a 10 -strain cocktail of $E$. coli O157:H7 at $\log _{10} 3.24-6.54 \mathrm{cfu} / \mathrm{ml}$ found a survival of

$14>300$ days along with evidence of biofilm formation on the container. The nature of these Gram

15 negative organisms allows for them to survive in water on traces of organic matter (Jay, Loessner

$16 \&$ Golden, 2005). In a study using effluent water from a waste water treatment plant to

17 hydroponically grow lettuce, the roots of lettuce plants were found to concentrate thermotolerant

18 coliforms, E. coli, and total coliforms (Keller, 2005). Along with organic matter, these roots

19 provided a surface for microbial growth and biofilm formation (Keller, 2005). This study

20 investigated the possibility of this using E. coli $\mathrm{O} 157: \mathrm{H} 7$ and red sails lettuce (Lactuca sativa) in

21 a hydroponic system. The purpose was to determine not only the likelihood and magnitude at

22 which internalization can happen within a hydroponic system but also the effect on potential 
1 internalization if the roots are damaged, possibly creating a large opening in which high

2 concentrations of the pathogen can possibly access the vascular system of the plant.

3

4

5

6

7

8 dried under UV light in a bio-safety cabinet. A V-shaped cut was made underneath the center

9 column to allow for air bubbles to escape, limiting their collision with the plant roots.

10

11

12

\section{MATERIALS AND METHODS}

\section{Hydroponic Tank}

Vermiculite was autoclaved and packed into the cells (1 sq.in., 2.5 in. deep) of the tray. Lettuce (Latuca sativa 'Red Sails') seeds were planted in each cell (2 per cell) with the exception of the middle column, on day 0 . The tray was then placed in a plastic 10 gallon nontransparent tank.

The tank was previously cleaned, then sanitized with a solution of ethanol, and left to air dry under UV light in a bio-safety cabinet before being filled with 27 L of sterile water. Importantly, this apparatus was left in the bio-safety cabinet for the duration of the study. A line was made on the inside of the tank to monitor loss of water; subsequently, distilled water was added when the level was visibly below the line. Water was only added post-sampling. Denim cloth was then placed over the gap between the edges of the polystyrene tray and the plastic bin to shield the water from the growth lights. A second smaller sized control tank was setup in a similar fashion, only filled with $12 \mathrm{~L}$ of distilled water.

A constant supply of air was pumped into the tanks to simulate conditions often seen in aquaponic and hydroponic system, providing motion of the water, even distribution of nutrients 
1 and microbial population, and oxygen. A 100 gallon Penn-Plax Whisper air pump feeding into a

2 sterile syringe filter $(0.2 \mu \mathrm{m}$ membrane) using $1 / 4$ " vinyl tubing ran air into a 4 -valve manifold.

3 From this the air was distributed evenly to both 12" air diffusers at the bottom of each tank. Each

4 tank had a 22" 15 watt T8 fluorescent plant grow light placed two inches above the trays. As the

5 lettuce grew, lights were raised accordingly. A one-part nutrient liquid hydroponic fertilizer

6 (FloraNova Grow) was dispensed into each tank according to the recommendations of 0.625

$7 \mathrm{ml} / \mathrm{L}$ at the time of seeding. The nutrient concentration in the water was monitored and measured

8 as an overall value in ppm using a Primo 2 EC and TDS tester (HI 70032) by Hanna Instruments.

Growing conditions

Temperature of both water and air were monitored. $\mathrm{pH}$ was kept between 6.5-7.5 and

12 adjusted accordingly with $1 \mathrm{M} \mathrm{NaOH}$ or $\mathrm{HCl}$. Concentrations of the hydroponic fertilizer were

13 periodically monitored, as was $\mathrm{pH}$, each day water samples were taken (Table 1) and stayed

14 between 661 and 816 PPM. The bio-safety cabinet was kept open 10 inches to allow for airflow.

15 Grow lights were kept on constantly due to them being on the lower level of required light for

16 plant growth. The lights were only turned off when the tank water was accessed to prevent

17 harmful UV light emissions from coming in contact with the microbial population.

Inoculation and monitoring of E. coli O157:H7

Escherichia coli O157:H7 ATCC strain 35150 (hereafter called E. coli) was used in this

21 experiment. One $\mathrm{ml}$ of $E$. coli was added to $19 \mathrm{ml}$ of tryptic soy broth (TSB) and incubated over 
1 night at $37^{\circ} \mathrm{C} .20 \mathrm{ml}$ of the above was then added to $380 \mathrm{ml}$ of TSB and incubated overnight to

2 obtain the desired volume of viable, pure culture cells $\left(10^{9} \mathrm{CFU} / \mathrm{ml}\right)$. On day $0,270 \mathrm{ml}$ of this

3 was added to the $27 \mathrm{~L}$ tank $\left(10^{7} \mathrm{CFU} / \mathrm{ml}\right)$. Viable cells were grown in TSB using a shaker

4 incubator and were added when cell count dropped below $10^{5} \mathrm{CFU} / \mathrm{ml}$ by first adding them to 90

$5 \quad \mathrm{ml}$ of phosphate buffer to promote even distribution.

$6 \quad$ Cell count was monitored every day until the system stabilized in which it was then done

7 in correlation with the cell death rate observed. This was done by inoculating serial dilutions of

8 the tank water on 3-M Petrifilm EC (E.coli/coliform plate). One $\mathrm{ml}$ of the water containing $E$.

9 coli was placed in $99 \mathrm{ml}$ of phosphate buffer, tilted 5 times to ensure even distribution, and then

10 plated on 3-M Petrifilm (1 ml). Four more $10^{-1}$ serial dilutions were made and plated. Petrifilm

11 was incubated for at $37^{\circ} \mathrm{C}$ for $48 \mathrm{~h}$; afterwards, colonies were counted according to standard

12 methods. Control water was also plated without diluting to check for contamination. This was

13 done every day until E. coli population stabilized; which it was then done according to

14 previously recorded reduction rate. Water samples were taken from both tanks on days 1-11, 14-

$1517,22,23,24,27,30,35,44,52,61$, and 73 . Additional E. coli grown in TSB (10 $\left.{ }^{9} \mathrm{CFU} / \mathrm{ml}\right)$ was

16 added on days $4,5,10,13,16$, and 18 at volumes $2,3,3,3,1$, and 2 ml to the tank containing $E$.

17 coli, respectively.

\section{Injury to lettuce roots}

To check if injury to the roots of the lettuce plants would affect the degree of

21 internalization, half of the cells containing lettuce plants growing in the tray containing E. coli

22 were randomly selected to receive injury. To access the roots, the tray was carefully lifted up out 
1 of the water and placed on a stand directly above the tank. The tips of the roots of the selected

2 plants were cut 3 consecutive times using a sterile pair of scissors over the course of twelve days,

3 starting 16 days before harvesting. Some of the plants roots did not grow through the

4 vermiculite to reach the water until after the first cut and consequently only received partial

5 treatment (2 cuts).

\section{Harvest and sterilization of lettuce}

To check for internalization of E. coli within the lettuce, the edible portions of the plants

9 were harvested and prepared for inoculation on 3-M Petrifilm. The lettuce plants were cut at the stem, approximately $1 \mathrm{~cm}$ above the vermiculite, and placed in a labeled bag according to their

11 cell after being weighed. Under UV light, each were dipped and swirled in a solution containing

12 deionized water, $10 \%$ bleach, and 3 drops of dish soap for approximately 10 seconds. They were

13 then dipped similarly in four containers of deionized water, successively. UV light was turned

14 off and lettuce was minced with a sterile scalpel blade and placed in a $50 \mathrm{ml}$ sterile plastic tube

15 containing $10 \mathrm{ml}$ of phosphate buffer. This was done for all samples from both the tank

16 containing E. coli and the control tank. Two samples from the control tank were done the same

17 way to verify they had no association with $E$. coli. Two other samples from the control tank were

18 first dipped in water containing E. coli $\left(10^{5} \mathrm{CFU} / \mathrm{ml}\right)$ before being sanitized to show

19 effectiveness of the technique.

The samples were then processed into a liquid form to be plated. Each sample was

21 homogenized until there was no reduction in particle size seen. This was done in the order of the

22 control samples being first, and ending with the samples that were dipped in the E. coli water; 
1 this minimized the risk of cross-contamination. The homogenizer was rinsed in $70 \%$ ethanol and

2 washed in 5 successions of phosphate buffer between each sample. The samples were then

3 filtered using a bag mixer for 60 seconds in $207 \mathrm{ml}$ sterile filter bags (330 micron pores) to

4 reduce remaining particles from the liquid. The filtered liquids were pipetted to individual $50 \mathrm{ml}$

5 sterile centrifuge tubes with plug caps. Each sample, pertaining to which cell the lettuce grew,

6 was plated on 3-M Petrifilm using $1 \mathrm{ml}$ of $10^{0},(2) 10^{2}, 10^{3}$, and $10^{4}$ dilutions. Petrifilms were

7 then incubated at $37^{\circ} \mathrm{C}$ for $48 \mathrm{hrs}$ to be counted and analyzed.

\section{$9 \quad$ Statistical Analysis}

All statistical analyses were done using SAS JMP11 software. Data were first

11 standardized to CFU/g and then converted to Log10 before taking the means. For comparing

12 treated to untreated plants, the p-value was found using Dunnett's method for comparisons with

13 a control. Tukeys HSD was used to compare untreated plants with both 2-cut treated and 3-cut

14 treated plants.

\section{RESULTS AND DISCUSSION}

204 with $1 \mathrm{M} \mathrm{NaOH}$. This was most likely due to uneven distribution of the nutrients in the

21 fertilizer from its sludge-like property. After day 4, the $\mathrm{pH}$ of the control tank was $6.90( \pm 0.05)$ 
1 and the $\mathrm{pH}$ of the tank containing $E$. coli was $7.45( \pm 0.02)$. The concentration of fertilizer was

2 between733-661 ppm for the control tank and 816-728 ppm for the E. coli tank. It was decided

3 not to add fertilizer during the experiment unless the plants looked malnourished or there was a

4 considerable drop in concentration, which was not seen.

The growth lights were initially on for 8 hours/day for the first 14 days. On day 14 it was

6 evident that the light source was insufficient, detected with a slight drooping of the leaves, and

7 was resultantly left on 24 hours a day to compensate. The temperature of the water and air

8 remained at a constant $24^{\circ} \mathrm{C} \pm 0.5$ and $23^{\circ} \mathrm{C} \pm 1$, respectively.

\section{Microbiological analysis of water}

Water samples were taken from both tanks to assess the concentration of E. coli.

12 Additional E. coli grown in TSB $\left(10^{9} \mathrm{CFU} / \mathrm{ml}\right)$ was added to the tank containing $E$. coli when

needed. The concentration of $E$. coli in the respective water showed a concentration as low as $10^{4}$

$14 \mathrm{CFU} / \mathrm{ml}$ (days 3 and 4) and as high as $10^{7} \mathrm{CFU} / \mathrm{ml}$ (day 1). The average concentration of E. coli

15 within the tank was $10^{6} \mathrm{CFU} / \mathrm{ml}$ (Table 1). There was no E. coli detected in any of the water 16 samples from the control tank.

It was necessary to add viable cells at higher concentrations than what was calculated in order for the volume of water to obtain the desired increase of microbial concentration. This was thought to be from a high initial death rate of the newly added $E$. coli due to the limited nutrients available and the high concentration of the established E. coli population already conditioned to

21 the environment. Therefore, larger amounts of newly added cells were necessary in order to 22 compensate for this initial drop upon addition. As time went on, the death rate of the established 
1 microbial community seemed to decrease and addition was needed less often in order to keep the

2 concentrations desired for the experiment.

$4 \quad$ Microbial Analysis of Lettuce

5

The two samples taken from the control tank that were not inoculated on the surface with E.coli were processed identically to the other lettuce samples. Neither of these samples showed any signs of $E$. coli growth on the selective media. This verified that there was no crosscontamination to the plants as well as no E. coli within the original seed. Both of the control samples dipped in the tank water containing E. coli $\left(10^{5} \mathrm{CFU} / \mathrm{ml}\right)$ before processing resulted in concentrations that were too few to count (TFTC). This verified the sanitation technique used and resulted in a 4-5 Log reduction of E. coli on the outer surface of the lettuce. It can be assumed that the lettuce plants growing in the tank that contained E. coli did not have a surface concentration of $E$. coli this high, if any at all, due to the precautionary measures taken to prevent plant contact with the water.

All samples from the tank containing E. coli were plated both directly and as a series of dilutions; this assured that each sample provided a plate within countable limitations, even for samples with high microbial concentrations. Counted CFU's were then standardized to CFU/g of lettuce and statistically analyzed to compare effectiveness of treatment. There was no significant difference between treated and untreated samples. Samples that had no injury manually exerted to their roots ranged from undetectable levels to $1.51 \times 10^{3} \mathrm{CFU} / \mathrm{g}$ with a mean value of $1.11 \times 10^{1}$ CFU/g. Samples that were subjected to have 2 cuts applied to their roots showed a range from undetectable levels to $4.90 \times 10^{4} \mathrm{CFU} / \mathrm{g}$ with a mean value of $8.66 \mathrm{CFU} / \mathrm{g}$. Samples that were 
1 subjected to have 3 cuts applied to their roots ranged from undetectable levels to $5.37 \times 10^{3} \mathrm{CFU} / \mathrm{g}$

2 with a mean value of $8.12 \times 10^{1} \mathrm{CFU} / \mathrm{g}$ (Table 2, Figure 1). These numbers are shown in Table 2

3 as Log based numbers due to the high standard deviation (SD) values seen. The largest mean

4 difference between the injured plants as compared to the uninjured plants was seen in the plants

5 subjected to having 3 cuts applied to their roots; having a mean difference \pm standard error (SE)

6 of $7.34 \pm 5.25 \mathrm{CFU} / \mathrm{g}$, and a p-value of 0.4650 (Table 2, Figure 2). In the plants that received 2

7 cuts because of their late manifestation into the water, the mean amount of internalized E. coli

8 was seen to be slightly lower than that of the uninjured roots with a mean difference of $1.28 \pm$

$95.89 \mathrm{CFU} / \mathrm{g}$ (Figure 2). This group had the sample with the highest observed CFU/g, while the

10 rest of the samples had no E. coli detected (Table 2). This may have been from the shorter roots

11 leaving less surface area and a shorter duration below the water surface.

This study provides supporting evidence of the possibility for E. coli $\mathrm{O} 157: \mathrm{H} 7$ to

13 internalize in lettuce. Previous studies have shown similar effects in both soil and soilless grown

14 leafy green produce without investigating the effect of plant root damage (Deering, Mauer \&

15 Pruitt, 2012; Keller, 2005; Solomon, Yaron \& Matthews, 2002) Even though the lettuce plants

16 with injury applied to their roots had the three highest E. coli concentrations seen, there was no

17 significant difference seen among the groups (Figure 3). This may be in part due to the injuries

18 occurring naturally within the tank to all of the plants. During the times in which the growing

19 tray was lifted to cut the plant roots, broken pieces of roots were already in the tank. This was

20 most likely due to the fragile nature of red sail lettuce plant roots along with the disturbance

21 caused by the oxygen mist bar in the water; despite the efforts made to reduce this effect.

22 Phenomena such as this can be expected in the commercial and agricultural setting of 
1 hydroponics but may have contributed to the high numbers of internalized E. coli within the

2 plants not subjected to manual injury.

3

4

5

6

17

\section{CONCLUSIONS}

E. coli $\mathrm{O} 157: \mathrm{H} 7$ was found to internalize in many of the plant samples. In some cases, this was seen to be as high as 3-4 Logs per gram of lettuce and as low as undetectable levels, showing the variation in which this may occur (Figure 1). The sample size for plants chosen to have injury inflicted was reduced as some of the plants' roots did not reach the water after the first treatment (cut) and had to be placed into a separate treatment group. Even though there was no significant difference of internalization between the injured and un-injured plants, there was a visual difference seen that could possibly show to be significant with a larger-scale hydroponic system (larger sample size). Important to note, some plants were damaged within the system itself. The suspected cause of this is due to the aeration of the water. This aeration may also have had an effect on the amount of internalization found within the untreated group. Further investigation should be done to determine the effect root injury to a plant may have on bacterial internalization.

\section{REFERENCES}

Al-Harbi. 2003. Faecal coliforms in pond water, sediments and hybrid tilapia Oreochromis niloticus x Oreochromis aureus in Saudi Arabia. Aquaculture !Research 34:517-524.

Deering, A. J., Mauer, L. J., \& Pruitt, R. E. (2012). Internalization of E. coli O157:H7 and salmonella spp. in plants: A review. Food Research International, 45(2), 567-575. doi:http://dx.doi.org.www.libproxy.wvu.edu/10.1016/j.foodres.2011.06.058 
Fox, B. K., Tamaru, C. S., Hollyer, J., Castro, L. F., Fonseca, J. M., Jay-Russell, M., \& Low, T. (2012). A preliminary study of microbial water quality related to food safety in recirculating aquaponic fish and vegetable production systems. College of Tropical Agriculture and Human Resources, University of Hawaii at Manoa. Food Safety and Technology.

Gomes, C., Da Silva, P., Moreira, R. G., Castell-Perez, E., Ellis, E. A., \& Pendleton, M. (2009). Understanding E. coli internalization in lettuce leaves for optimization of irradiation treatment. International Journal of Food Microbiology, 135(3), 238-247. doi:http://dx.doi.org.www.libproxy.wvu.edu/10.1016/j.ijfoodmicro.2009.08.026

Jay, J., Loessner, M. \& Golden, D. (2005). Miscellaneous Food Products. In Modern food microbiology (7th ed., p. 210). New York: Springer.

Keller, R. (2005). Hydroponic cultivation of lettuce (lactuca sativa) using effluents from primary, secondary and tertiary UV treatments. Water Science \& Technology.Water Supply, 5(1), 95. Retrieved from CAB Abstracts 1990-Present database.

Koseki, S., Mizuno, Y., \& Yamamoto, K. (2011). Comparison of two possible routes of pathogen contamination of spinach leaves in a hydroponic cultivation system. Journal of Food Protection, 74(9), 1536-42. Retrieved from http://search.proquest.com.www.libproxy.wvu.edu/docview/889264892?accountid=2837

Macarisin, D., Patel, J., \& Sharma, V. K. (2014). Role of curli and plant cultivation conditions on escherichia coli O157:H7 internalization into spinach grown on hydroponics and in soil. International Journal of Food Microbiology, 173(0), 48-53. doi:http://dx.doi.org.www.libproxy.wvu.edu/10.1016/j.ijfoodmicro.2013.12.004

Penn State Extension (2014). Selected Irrigation Water Standards (Farm Food Safety (Penn State Extension)) http://extension.psu.edu/food/safety/farm/resources/water/selectedirrigation-water-standards

Solomon, E. B., Yaron, S., \& Matthews, K. R. (2002). Transmission of Escherichia coli 
O157:H7 from contaminated manure and irrigation water to lettuce plant tissue and its subsequent internalization. Applied and Environmental Microbiology, 68(1), 397-400. Retrieved from http://search.ebscohost.com.www.libproxy.wvu.edu/login.aspx?direct=true \&db=ffh\&AN $=2002-05-J q 1093 \&$ site $=$ ehost-live

Timmons, M., \& Ebeling, J. (2007). Aquaponics: Integrating Fish and Plant Culture. In Recirculating aquaculture (2nd ed., p. 807). Ithaca: Cayuga Aqua Ventures.

U.S. Department of Agriculture (2014). Hydroponics. Retrieved from http://afsic.nal.usda.gov/aquaculture-and-soilless-farming/hydroponics

Zheng, J., Allard, S., Reynolds, S., Millner, P., Arce, G., Blodgett, R. J., \& Brown, E. W. (2013). Colonization and Internalization of Salmonella enterica in Tomato Plants. Applied and Environmental Microbiology, 79(8), 2494-2502. doi:10.1128/AEM.0370412 
1 Figure 1: Descriptive analysis showing variation between data points for the Log of E. coli O157:H7 per gram of lettuce subjected to 2 injury. Line within the box represens the median, the upper and lower quadrants represent $75^{\text {th }}$ and $25^{\text {th }}$ percentile, respectively, while 3 the whiskers of the box represent maximum and minimum data points.

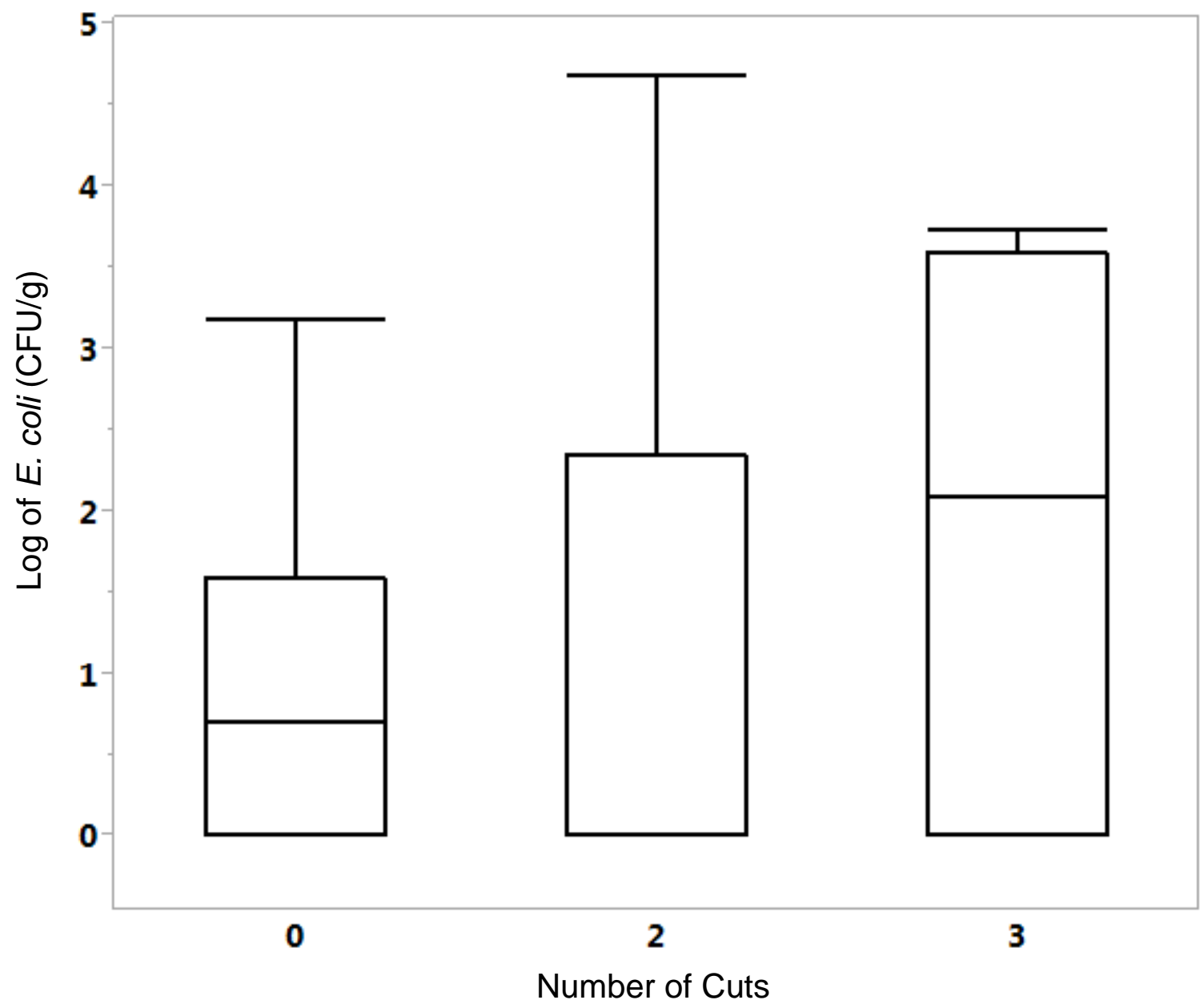


1 Figure 2: Mean Log $+\mathrm{SE}$ of $E$. coli $\mathrm{O} 157: \mathrm{H} 7$ per gram of lettuce with amount of injury administered. Different letters on the top of 2 the data bars indicate significant difference $(\mathrm{P}<0.05)$.

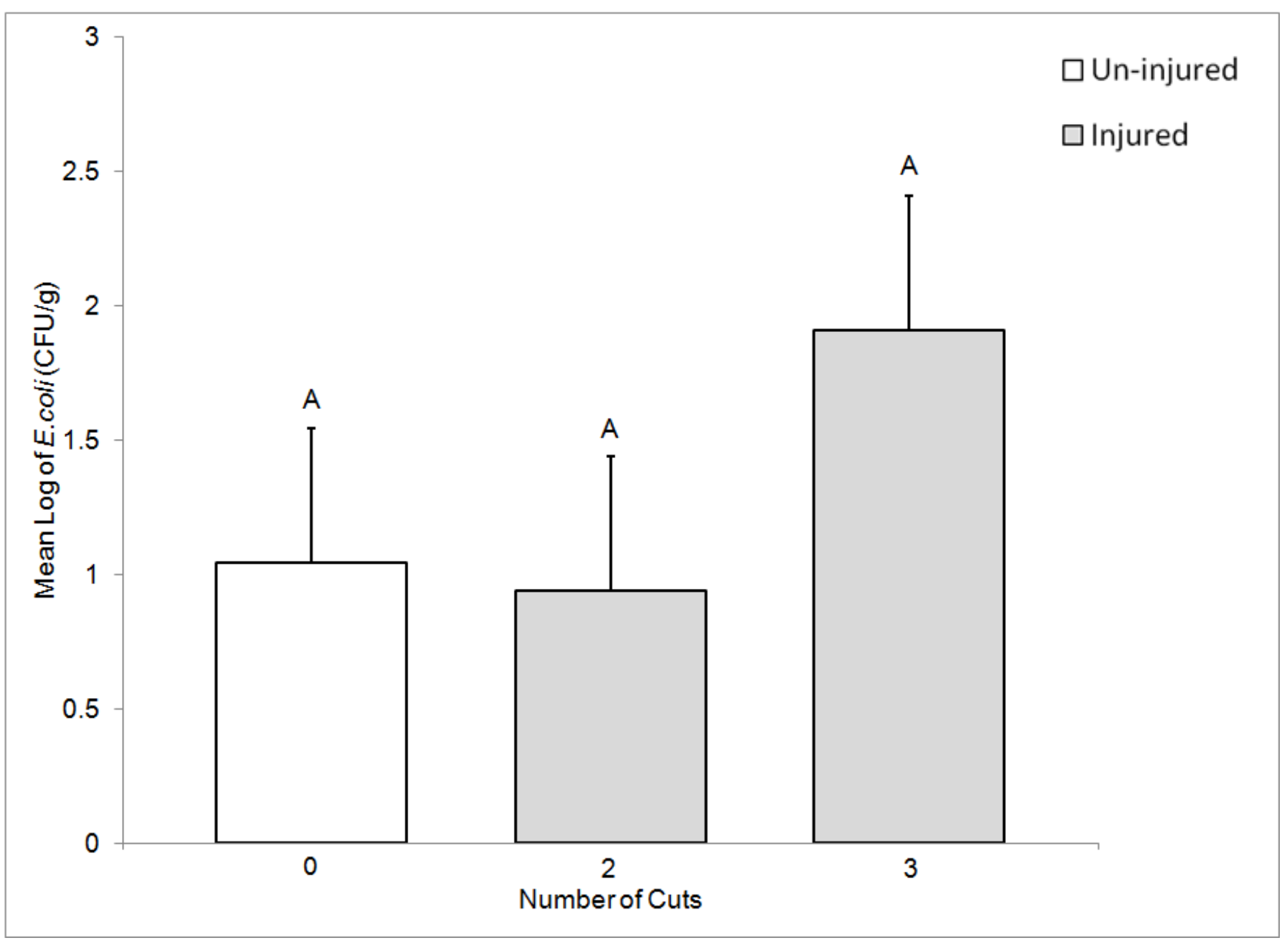


1 Figure 3: Mean Log + SE of E.coli O157:H7 per gram of lettuce subjected injury. Different letters on the top of the data bars indicate 2 significant difference $(\mathrm{P}<0.05)$.

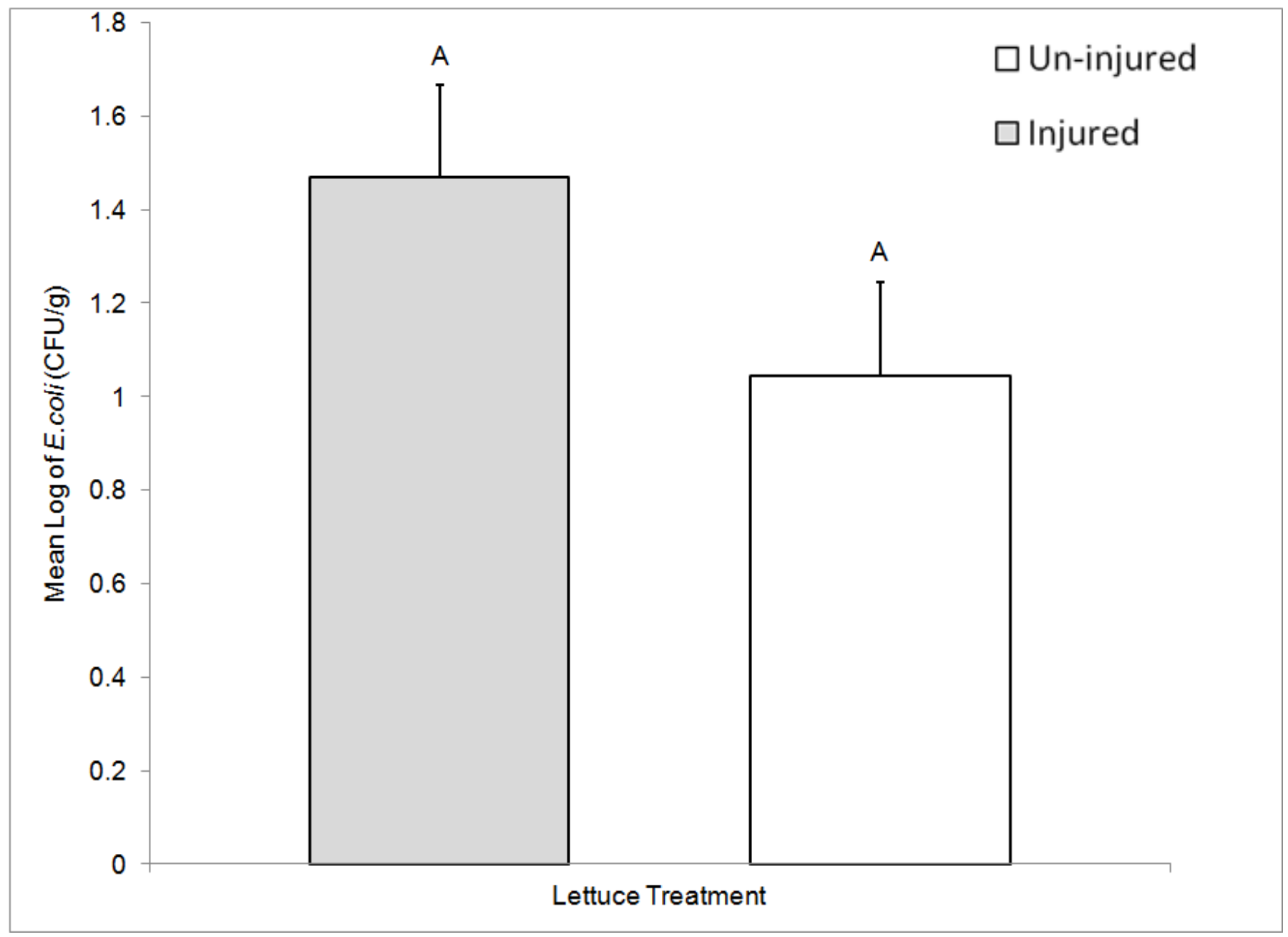


1 Table 1. Concentration of E. coli in the water for each day it was sampled and volume of pure culture added at various time intervals $2\left(10^{9} \mathrm{CFU} / \mathrm{ml}\right)$.

3

4

5

6

7

8

9

10

11

12

13

14

15

16

17

18

19

20

\begin{tabular}{ccc} 
Day & $\begin{array}{c}\text { E. coli in } \\
\text { water } \\
(\text { CFU/ml) }\end{array}$ & $\begin{array}{c}\text { Pure Culture } \\
\text { Added }(\mathrm{ml})\end{array}$ \\
\hline 1 & $2.30 \mathrm{E}+07$ & \\
2 & $3.00 \mathrm{E}+06$ & \\
3 & $2.00 \mathrm{E}+04$ & \\
4 & $4.00 \mathrm{E}+04$ & 2 \\
5 & $3.00 \mathrm{E}+05$ & 3 \\
6 & $5.00 \mathrm{E}+05$ & \\
7 & $3.00 \mathrm{E}+05$ & \\
8 & $3.00 \mathrm{E}+05$ & 3 \\
9 & $6.00 \mathrm{E}+05$ & \\
10 & $8.00 \mathrm{E}+05$ & \\
11 & $4.00 \mathrm{E}+05$ & 3 \\
14 & $1.00 \mathrm{E}+06$ & \\
15 & $1.00 \mathrm{E}+06$ & \\
17 & $3.00 \mathrm{E}+05$ & \\
22 & $4.00 \mathrm{E}+05$ & \\
24 & $4.00 \mathrm{E}+05$ & 2 \\
27 & $4.00 \mathrm{E}+05$ & \\
30 & $2.00 \mathrm{E}+05$ & \\
35 & $8.00 \mathrm{E}+05$ & \\
44 & $9.00 \mathrm{E}+05$ & \\
52 & $1.00 \mathrm{E}+06$ & \\
61 & $2.00 \mathrm{E}+05$ & \\
73 & $1.00 \mathrm{E}+05$ & \\
& &
\end{tabular}


1 Table 2. Statistical measures including highest seen concentration of E. coli (Max CFU), mean values \pm standard deviation (SD), and 2 mean difference \pm standard error (SE).

\begin{tabular}{|c|c|c|c|c|}
\hline \multirow[b]{3}{*}{ Injury Applied } & \multirow{2}{*}{\multicolumn{4}{|c|}{ E. coli O157:H7 Log (CFU/g) }} \\
\hline & & & & \\
\hline & Mean \pm SD & Max CFU & Mean Difference \pm SE & p-Value \\
\hline 2 Cuts $(n=5)$ & $0.9377 \pm 2.10$ & 4.69 & $0.1062 \pm 0.77$ & 0.9896 \\
\hline 3 Cuts $(n=6)$ & $1.9096 \pm 1.78$ & 3.73 & $0.8657 \pm 0.72$ & 0.4650 \\
\hline Untreated $(n=15)$ & $1.0439 \pm 1.13$ & 3.18 & & \\
\hline
\end{tabular}

